\title{
Patterns of the electric organ discharge during courtship and spawning in the mormyrid fish, Pollimyrus isidori
}

\author{
B.O. Bratton* and B. Kramer \\ Zoologisches Institut der Universität, Universitätsstrasse 31, D-8400 Regensburg, Federal Republic of Germany
}

Received December 31, 1987 / Accepted June 14, 1988

Summary. Pollimyrus isidori's electric organ discharge (EOD) is of the pulse type. Patterns of EOD intervals were investigated prior to, during and following spawning behaviors as related with overt behaviors, and with the sound production by the nestbuilding male. Prior to the time of reproduction, isolated and socially interacting fish $(n=15)$ showed characteristic discharge interval patterns for resting, swimming, probing, hovering and hiding activities. Males $(n=8)$ and females $(n=6)$ did not differ in their mean EOD repetition rates during resting $(11.6 \pm 2.5 \mathrm{~Hz})$, nor Short Bursts/min (less than 20 intervals of $8-13 \mathrm{~ms}$ ). In interacting fish Long Bursts (greater than 20 intervals of $8-13 \mathrm{~ms}$, lasting for more than $300 \mathrm{~ms}$ ) were observed only during the attack and bite sequence. A pursuing fish displayed a rapid alternation of Long Bursts with Discharge Breaks (300-1000 ms silence) during the chase behavior. Avoidance behavior which followed from several attacks was correlated with a Medium Uniform Rate $(8-12 \mathrm{~Hz})$ normally lasting for 20 to $60 \mathrm{~s}$, or a Discharge Arrest (silence greater than $1 \mathrm{~s}$ ) in the submissive fish. The nocturnal courtship behavior began soon after dark $(1900 \mathrm{~h})$. Spawning typically started 2 to $5 \mathrm{~h}$ after dark, continuing for 2 to $6 \mathrm{~h}$ until about $0200 \mathrm{~h}$. During courtship and spawning the female's brief visits (15-25s) to the male's territory recurred every $30-60 \mathrm{~s}$. At all other times the female was aggressively excluded from the nest region. Courtship and spawning behaviors are described along with the electrical displays identified from 19 spawnings in three fish pairs (from a total of 37 spawnings in 4 males and 4 females). Just

* Present address: Department of Zoology, The University of Oklahoma, Norman, Oklahoma 73019, USA

Offprint requests to: $\mathrm{B}$. Kramer prior to the onset of courtship behavior, with male territorial aggression beginning to decline, females switched from a Medium Sporadic Rate pattern (resting and hiding patterns; $13 \mathrm{~Hz}$ ) to a Medium Uniform Rate pattern $(6-8 \mathrm{~Hz})$ while still in their hiding area. Females continued to display this uniform rate throughout the courtship and spawning period, including the courtship and spawning bouts when Discharge Breaks or Arrests also occurred. This persistance distinguishes the courtship pattern from the similar avoidance pattern (see above). The male courtship and spawning EOD pattern was similar to the female's and unique for a territorial male. He switched from a High Sporadic Rate (swimming EOD pattern; about $18 \mathrm{~Hz}$ ) to a regularized Medium Uniform Rate (about 9 to $11 \mathrm{~Hz}$ ) only during courtship and spawning bouts, including 1-3 EOD Breaks during Vent-toVent coupling (average interval: $272 \pm 71 \mathrm{~ms}, n=$ 37). No sooner had the female left the spawning site than he resumed displaying a High Sporadic Rate. This temporal correlation of reproductive behaviors with electrical displays suggests their instrumental role in mutual acceptance of mates. Males showed their sex-specific type of EOD phase-locking, the Preferred Latency Response, only during the first few hours of entry of a fish in their tank. Two females with EOD waveform features more typical of males also spawned repeatedly; waveform does not appear to be critical. Males stopped their nocturnal sound production for the later part of courtship and the whole spawning period. Except for infrequent attacks on the female between spawning bouts, the male did not resume singing until the end of spawning when all eggs were shed (around $0200 \mathrm{~h}$ ); from this time on the male sang until dawn. The sequencing of the three acoustic elements (moans, grunts, growls) 
are described. A catalogue of discharge patterns correlated with overt behaviors (Tables 1,2), and an integrated summary time table of $P$. isidori's complex reproductive behavior are presented.

\section{Introduction}

The freshwater teleost fishes of the African family Mormyridae produce weak pulse-type electric organ discharges (EODs) for communication (suggested by Möhres 1957 and Lissmann 1958; first documented by Szabo (in Lissmann 1961); further evidence by Moller 1970; Moller and Bauer 1973; Bauer 1974; see also Szabo and Moller 1984), and location of nearby objects ( $<10 \mathrm{~cm}$ away) (Lissmann 1958; Belbenoit 1970; Harder 1972; Heiligenberg 1977; Push and Moller 1979). Three types of lateral line derived electroreceptors in the skin code for the fish's own and other fields, with the Knollenorgane probably encoding the electric communication signals received from nearby fish (see reviews by Bennett 1971; Szabo and Fessard 1974; Bell 1979, 1986; Bullock 1982; Zakon 1986). The distance of communication is around $1 \mathrm{~m}$ in a small mormyrid, Brienomyrus niger (Squire and Moller 1982).

Several modes of electrical communication are seen in mormyrids. Characteristic discharge interval patterns accompany aggression, fleeing and appeasement; for example, discharge rate accelerations and pauses (Bauer 1972; Bauer and Kramer 1974; Bell et al. 1974; Kramer 1974, 1976a, 1976 b, 1976c; Kramer and Bauer 1976). A diversity of display patterns was also found in Pollimyrus isidori (Kramer 1978). A communicative role of some of these patterns have been experimentally shown in playback studies (Kramer 1979; Lücker 1982, 1983).

Mormyrids may also communicate by phaselocking their EODs to those of another fish, the Preferred Latency (PLR) or echo response (Bauer and Kramer 1974; Russell et al. 1974; Kramer 1974). Adult female $P$. isidori display a Preferred Latency Avoidance (PLA) instead of the male response of a PLR at 10-15 ms latency (Kramer 1978; Lücker and Kramer 1981). The functional significance of this divergence among the sexes is, however, still unclear.

The waveform of $P$. isidori's extremely short EOD pulse (less than $250 \mu \mathrm{s}$ ) varies individually (Lücker and Kramer 1981), and mate recognition by EOD waveform cues has been suggested by Westby and Kirschbaum (1982) on the basis of their thorough investigation into intraspecific variability. However, because of extensive statistical overlapping between the sexes, and a marked dependency of the EOD waveform on water conductivity, Bratton and Kramer (1988) consider this mechanism a rather unlikely possibility in $P$. isidori (for other species see review Hopkins 1986; and review in Bratton and Kramer 1988).

Male $P$. isidori "sing" acoustically preluding spawning behavior (Crawford et al. 1986; confirmed by our own observations). There have been, as yet, no experimental studies on the functional significance of this communication modality.

Descriptions of electrical communication signals during breeding behaviors are, however, lacking. One of the reasons for this may be the technical difficulties of signal separation of two or more interacting fish (Bell et al. 1974; Kramer 1974, 1976b). In the present study we correlate the EOD interval patterns of mating pairs to the courtship and spawning behavior. By their behavioral context and relative timing, we conclude that stereotyped discharge interval patterns are instrumental for mutual acceptance of the mates during courtship and spawning (see also Bratton 1987).

\section{Methods}

\section{Animals and animal care}

Our Pollimyrus isidori (Cuvier and Valenciennes 1846) were wild caught and imported from Ikea, Nigeria. Sex was determined by distinguishing mature males as having a concave indentation along the anal fin base (not distinct in all males), and females as having a straight fin base (Lücker and Kramer 1981); standard body length varied from 75 to $82 \mathrm{~mm}$. Additionally, the male Preferred Latency Response (PLR) and the female display of a Prefered Latency Avoidance (PLA) were used for sex determination as the more reliable technique (sec below).

Fish of the general laboratory stock (78 fish) were kept in $2001(80 \times 50 \times 50 \mathrm{~cm}$ high $)$ community tanks; the largest fish were chosen for breeding. Temperature was $27 \pm 2^{\circ} \mathrm{C}$; conductivity: $100 \pm 5 \mu \mathrm{S} / \mathrm{cm}$; $\mathrm{pH}: 7.5$; photoperiod: $12: 12 \mathrm{~h} \mathrm{~L}: \mathrm{D}$, without dimming. Fish were fed daily on Chironomus larvae, and supplied with porous tube hiding places and plants. Fish were transferred between aquaria in a small 11 tank instead of being netted.

\section{Spawning tanks and conditions}

Nine spawning tanks $(1201,75 \times 40 \times 40 \mathrm{~cm}$ high; or 3601 , $60 \times 120 \times 50 \mathrm{~cm}$ high) for 2 to 4 fish were established in order to induce spawning in $P$. isidori. These "natural tanks" contained sand or gravel bottoms, aquatic plants (floating fern plant Ceratopteris thalictroides, and Vesicularia dubyana or 'Java-moss', an aquatic moss used for nesting material), hiding tubes and rocky nest sites. Water was power-filtered through synthetic fiber and peat and returned to the tank through over- 
head sprinklers ( 5 tanks) to imitate rain. Water conductivity was lowered with deionized water starting at $200-300 \mu \mathrm{S} / \mathrm{cm}$ and decreasing to $80-100 \mu \mathrm{S} / \mathrm{cm}$ over a period of 4 to 6 weeks with water levels remaining near constant. Overhead lamps provided a $12 \mathrm{~h}: 12 \mathrm{~h}$ light-dark cycle $(0700$ to $1900 \mathrm{~h})$.

Among the methods of bringing $P$. isidor $i$ into breeding condition (Kirschbaum 1984, 1987), primarily slowly decreasing water conductivity and imitation of rain were successful. Altering levels of water was not necessary in our fish, except for replacement from evaporation. In 4 tanks without artificial rain spawning never occurred. Perhaps also important for inducement to spawn was the availability of nesting materials and nest locations for the male, as well as sufficiently dense plants and a hiding tube for the female near the surface; sometimes a glass tank partition was installed.

\section{EOD recordings from spawning fish}

Two separate electrode arrangements were used. Two orthogonally oriented pairs of electrodes $(25 \mathrm{~cm}$ separation of + and - poles) were positioned over the male's hiding tube and nesting-spawning region near the bottom, while a third electrode pair ( $8 \mathrm{~cm}$ separation) was positioned above the female's tube near the surface of the tank. The electrodes consisted of carbon rod pairs ( $6 \mathrm{~mm}$ diameter, $1-4 \mathrm{~cm}$ long). The differentially amplified signals $(100 \times, 3 \mathrm{~Hz}-100 \mathrm{kHz})$ from the two electrode pairs monitoring the male's region were full-way rectified and summed. Electronic separation of the male's signals from the female's were by amplitude difference, using an electronic 'window' discriminator when fish were in their respective region. The two series of EOD intervals were measured concurrently using either a Nicolet 1074 digital analyzer, or a twochannel clock counter module controlled by a microcomputer set at $0.1-0.5 \mathrm{~ms}$ resolution. Programs written in PASCAL were used for immediate screen data plotting and storage of $2 \times 8000$ intervals to disk.

When one or both fish were $15-25 \mathrm{~cm}$ away from the centers of their respective home regions the EODs could not be separated electronically; rather the EOD intervals were measured by hand from oscilloscope films (Agfa-Gevaert; Oscilloscript-2) off magnetic tape recordings using a vernier scale $(1 \mathrm{~m} /$ s film speed past the open shutter, Tönnies Recordine camera; see Kramer 1976b, 1978). Although distorted the individual EODs could still be discriminated from playbacks off the magnetic tapes recorded on a Nagra IV SJ tape recorder $(19 \mathrm{~cm} / \mathrm{s}$, $25 \mathrm{~Hz}-20 \mathrm{kHz} \pm 1.0 \mathrm{~dB}$; see Kramer and Weymann 1987 ).

Analysis of the data was achieved by off-line computer programs (Hewlett-Packard HP-9825B for plotting on a HP$9872 \mathrm{~A}$ plotter). Means are given with their standard deviations and were tested for significant differences by the $t$-test (Sachs 1978).

\section{EOD recordings in aggression experiments}

Aggression was studied when occurring spontaneously in spawning tanks, and in a $250 \mathrm{l}$ experimental all-glass tank where two-dimensional video recording was possible (including the view from underneath by using a $45^{\circ}$ mirror). In the experimental tank, full separation of the EODs of interacting fish was achieved electronically (see below).

Before tests the fish were isolated for at least three days in separate tanks; "resident fish" (male or female) were placed into the $250 \mathrm{l}$ experimental tank $(50 \times 100 \times 50 \mathrm{~cm}$ high $)$ with silver wire wall electrodes where fish remained for the whole test period. The test fish was put into a 401 tank; for a test

the fish was fitted with a fine copper wire $(60 \mu \mathrm{m}$ diameter, $65 \mathrm{~cm}$ long; insulated except for $2 \mathrm{~mm}$ near the fish) around its caudal peduncle (slip-knot loop around tail) and entered into the 2501 electrode tank (without plants) where the unwired resident fish waited in a porous tube. The tube, open at both ends ( $9 \mathrm{~cm}$ long, $4.5 \mathrm{~cm}$ inner diameter), contained a slitted roof lengthwise for wire passage. A plastic screen enclosure kept both fish $10 \mathrm{~cm}$ away from the electrodes. A 3-60 min (sometimes several hours) recording followed before the wired fish was removed, untethered and placed back into its home tank. Before and after a session, a 3 min recording of both isolated fish was made.

Electronic separation of the EODs of the two fish was by a logic circuit with two inputs and separate outputs for each fish. One input was from the two pairs of tank electrodes (signals amplified, rectified and summed), the other from the wire

Table 1. List of principal behaviors associated with the electric organ discharge in Pollimyrus isidori. Abbreviations at right are used elsewhere in the text

\section{General overt behaviors}

Individual and swimming behaviors:

Resting Motionless

Hiding (moving fins, near cover)

Probing/Foraging (food or materials)

Hovering (stationary with fin motion, away from cover)

Slow Swimming $(<2 \mathrm{~cm} / \mathrm{s})$

Moderate Swimming

Vigorous Swimming $(>5 \mathrm{~cm} / \mathrm{s}$ )

Agonistic behaviors:

Approach (threat before contact)

Circling (before attack)

[SS]

$[\mathrm{MS}]$

[VS]

Attack

[AP]

[CL]

[AT]

Bite (contact)

Chase (pursue by vigorous swimming)

[BT]

Fleeing (retreat by vigorous swimming)

[CH]

Avoidance (by slow swimming or hovering)

]FL]

[AV]

Reproductive social behaviors

Courtship behaviors:

Nest Building

Courtship Attack (male attacking female)

Head-to-tail Circling

Vent-to-Vent coupling

Rotation (follows vent-to-vent)

Acoustic signal (male)

Moan

Grunt

Growl

Hoot

[NB]

[CA]

$[\mathrm{HC}]$

[VV]

[RO]

[MO]

[GT]

[GL]

[HO]

Spawning behaviors:

Female stay (Wait) in her Territory

Territory Patrolling (male)

Female Spawning site wait $(1-2 \mathrm{sec})$

Oviposition (egg laying)

Quiver Return (female)

Egg Transport (male)

Nest Nudging

End of Spawning (female hiding \& resting) 
around the fish's tail. The wire signal blanked the other fish's output line for a $0.3 \mathrm{~ms}$ period while the wired fish output line required both inputs to be active simultaneously. This method is similar to that used by Bell et al. (1974) and afforded a better than $95 \%$ reliability of EOD separation.

\section{PLR/PLA-latency tests for sex discrimination}

All experimental subjects were tested for their type of phaselocking behavior which is PLR in males and PLA in females (Kramer 1978; Lücker and Kramer 1981). Fish were isolated in a 1201 tank with a central porous hiding tube for 24 to $48 \mathrm{~h}$ before testing which was performed during daylight hours. The stimulus electrodes consisted of two vertically oriented carbon rods $(8 \mathrm{~cm}$ apart, $1 \mathrm{~cm}$ long) placed $6 \mathrm{~cm}$ parallel to the hiding tube.

Fish were stimulated with a free-running train of $0.2 \mathrm{~ms}$ monopolar square wave pulses at $10 \mathrm{~Hz}$ generated by a GrassS88 pulse generator, isolated from ground by a Grass-SIU5 stimulus isolation unit. Stimulus amplitude was $20 \%$ above the peak-to-peak amplitude of the EOD; pulse separation was by amplitude using a 'window' discriminator.

\section{Acoustic recordings and analyses}

The male's acoustic sounds were monitored with a centrally located hydrophone (Brüel and Kjær model 8101 with built-in preamplifier; $1 \mathrm{~Hz}$ to $80 \mathrm{kHz} \pm 2 \mathrm{~dB}$ ) connected to a Brüel and Kjær model 2610 measuring amplifier $(2 \mathrm{~Hz}-200 \mathrm{kHz})$. The output was recorded onto magnetic tape using the third (FM) track of a Nagra tape $(0 \mathrm{~Hz}-4 \mathrm{kHz},-3 \mathrm{~dB})$, or a Revox A77 recorder $(30 \mathrm{~Hz}-20 \mathrm{kHz}+2 /-3 \mathrm{~dB}$ at $19 \mathrm{~cm} / \mathrm{s})$.

Sonograms were made on a Kay Electronics Co. Digital Sona-Graph (model 7800) by tape playback to the analyzer (filters: $5.27 \mathrm{~Hz}-1000 \mathrm{~Hz} ; 20$ s digitized record).

\section{Behavioral observations}

The behavior of the fish was recorded using a Grundig BK-300 video system and two cameras (Grundig FA-70) with white light illumination or during night hours with an infrared camera (Grundig FA-70H) and two infrared illumination sources positioned above the tank. A second camera viewed a digital EOD counter that began with the first recorded EOD to the interval counter.

\section{Results}

\section{Non-reproductive EOD interval patterns}

EOD interval patterns during rest and swimming (light phase). Undisturbed, isolated animals at rest (Resting Motionless with only operculum movements) displayed a Medium Sporadic Rate sequence containing intervals centered on $80 \mathrm{~ms}$ ranging from 9 to $340 \mathrm{~ms}$ (mean EOD rate $f=$ $11.7 \pm 2.1 \mathrm{~Hz}$; 8 fish) with Short Bursts ( $<20$ intervals of 8-13 ms) interspersed every 5-10 s (Fig. 1 a; see also Kramer 1978). These contained the shortest intervals possible for $P$. isidori (Maximum Species $\operatorname{Rate}=125 \mathrm{~Hz}$ ).
The interval pattern for Hiding (slow fin movement while hiding within a tube or near plants) resembled the resting pattern, but without the short bursts that are so characteristic of resting fish (Fig. 1 b). As fish began slowly moving about to Probe and Forage for food or nest materials, their EOD frequency increased, but with many Discharge Breaks (a break: $300 \mathrm{~ms}$ to $1 \mathrm{~s}$; Fig. 1c).

Fish also showed a characteristic Medium Uniform Rate sequence while Hovering (moving their fins while remaining in place) in regions away from tubes and plants $(10 \mathrm{~Hz}$ in Fig. $1 \mathrm{~d})$ with a very narrow histogram peak centered on about $90 \mathrm{~ms}$. During Moderate Swimming (about $27 \mathrm{~Hz}$ in Fig. 1f) a High Sporadic Rate sequence with a broad single mode histogram was devoid of Short Bursts and Discharge Breaks (see also Kramer 1978). The EOD patterns during Slow, Moderate and Vigorous Swimming differed clearly from Resting, with its Short Bursts, and from Hovering, with its Medium Uniform Rate pattern. Other behaviors showed combinations of patterns such as Slow Swimming $(19 \mathrm{~Hz}$, broad histogram in Fig. 1e), containing elements of the Moderate Swimming and Hovering patterns, while Probing ( $22 \mathrm{~Hz}$ in Fig. $1 \mathrm{c}$ ) resembled Slow Swimming with the additional short Discharge Breaks.

These patterns which were studied in isolated ( $n=15 ; 38$ sessions) and paired fish $(n=14 ; 28$ sessions) did not show any differences between 8 males and 6 females in the mean EOD rates, the interval ranges, the lengths of the bursts, and the shortest intervals of a burst (combined mean: $11.9 \pm 1.5 \mathrm{~ms}$; difference between the sexes not significant with $P>0.43$ ). The combined mean resting frequency was $11.6 \pm 2.5 \mathrm{~Hz}(P>0.14)$. The average number of bursts per min for resting fish was $6.8 \pm 5.1(P>0.26)$.

EOD interval patterns during aggression. Aggression was studied in paired fish (EOD separation by wire method, light-phase) and in spawning tanks, as fish were attacked by residents (darkphase). Attacks occurred with a Long Burst (> 20 intervals at $8-13 \mathrm{~ms}$ ) usually from both fish (in male/male and male/female pairs) before dominance was established. In contrast to the short bursts during rest, an attack burst could be much longer ( $>300 \mathrm{~ms}$ ) and corresponded to close Approach (AP in Fig. 2) or physical contact (Bite; see also Kramer 1978), as also observed in Gnathonemus petersii (Kramer and Bauer 1976). A highfrequency burst ended abruptly with a long interval, similarly to $G$. petersii (Kramer and Bauer 1976). Aggressive resident fish, attacking in quick 

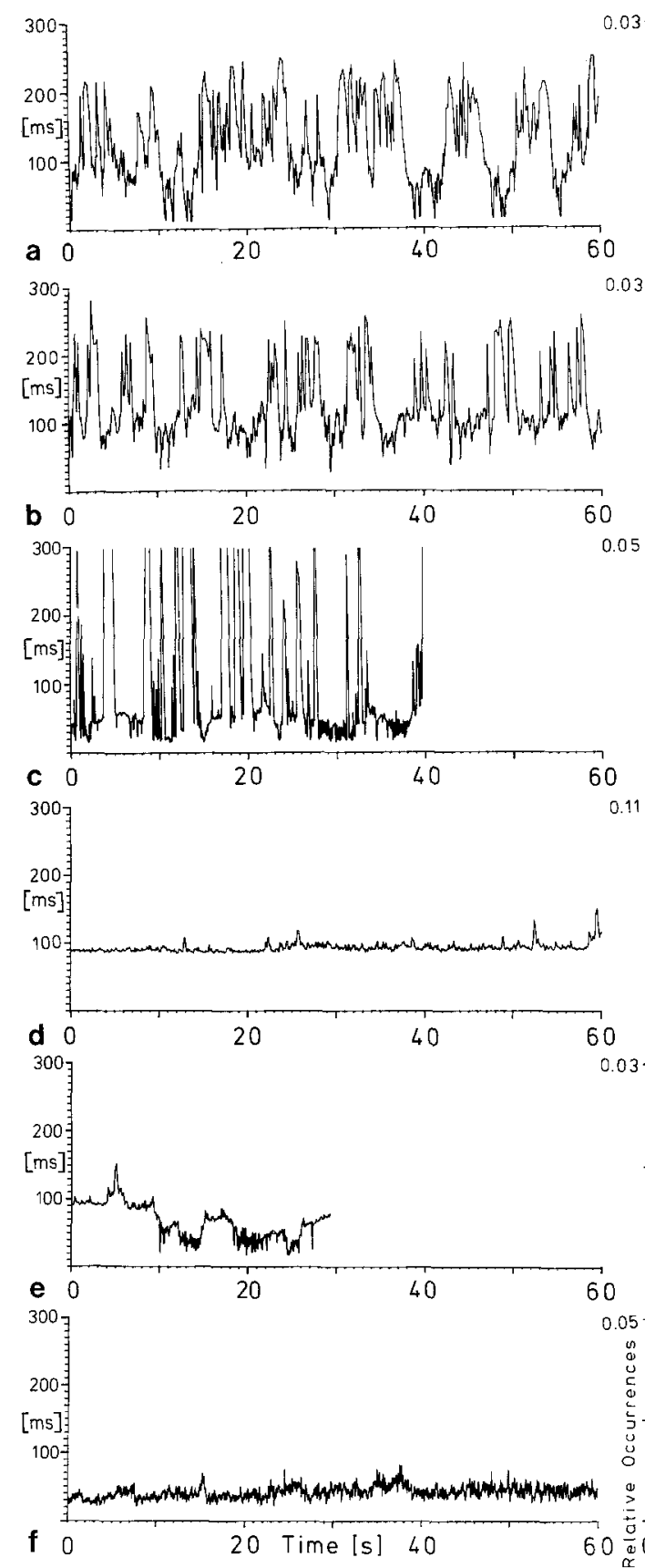
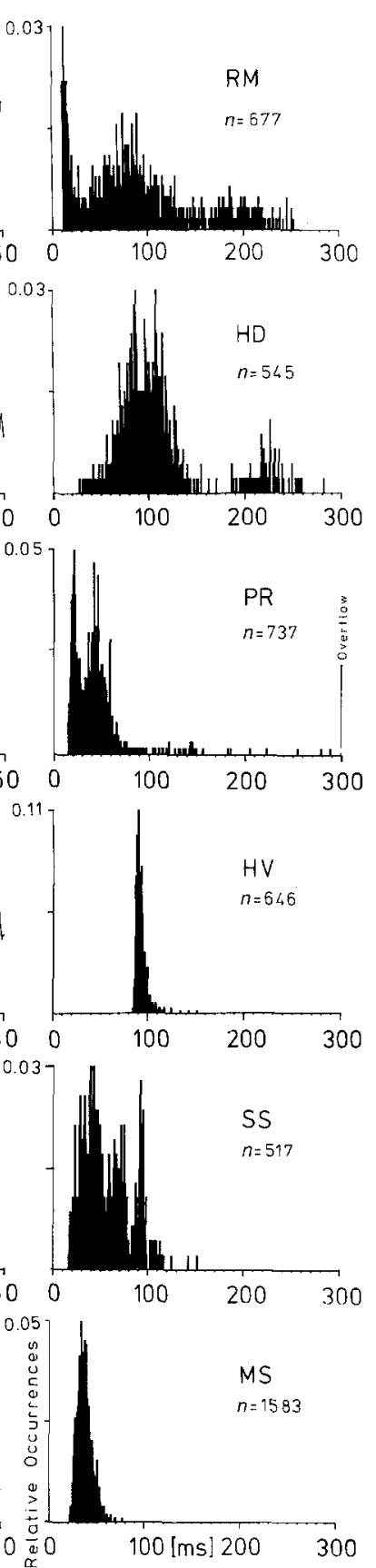

Fig. 1 a-f. Sequential inter-discharge interval plots (left) and interval histograms (right) accompanying 6 overt behaviors during the daylight phase: a Resting Motionless $(R M ; f=13.2 \mathrm{~Hz}$; showing three modes: $11 \mathrm{~ms}, 80 \mathrm{~ms}$ and 180-200 ms).

b Hiding ( $H D ; f=10.5 \mathrm{~Hz}$; bimodal at $90 \mathrm{~ms}$ and $220 \mathrm{~ms}$ but without the $11 \mathrm{~ms}$ burst mode).

c Probing/Foraging $(P R ; f=22 \mathrm{~Hz})$.

d Hovering $(H V ; f=10.8 \mathrm{~Hz})$.

e Slow Swimming $(S S ; f=19 \mathrm{~Hz})$.

f Moderate Swimming $(M S ; f=28.3 \mathrm{~Hz}$ ). Axes of left diagrams: abscissa is time $(60 \mathrm{~s}$ in $\mathrm{a}-\mathrm{f})$; ordinate is length of each inter-EOD interval (in ms). Histograms on the right represent data to their left ( $n=$ total number of EODs analyzed). Axes of right diagrams: abscissa is interdischarge intervals in ms; Ordinate: relative occurrences of EOD intervals per $1 \mathrm{~ms}$ bins. Bin 300 is overflow

succession, showed Discharge Breaks (intervals 300-1000 ms) and Discharge Arrests (a silence lasting longer than $1 \mathrm{~s}$ ) during the Chase period (Fig. 3). Following several attacks the submissive fish swam vigorously away from the dominant fish. Fish that were attacked several times typically became silent (several seconds to minutes), or displayed a steady discharge of Medium Uniform Rate around $12 \mathrm{~Hz}$ (see also Kramer 1976a for similar patterns in $G$. petersii).

\section{Reproductive behavior in Pollimyrus isidori}

Spawning behavior has already briefly been described by Crawford et al. (1986) with an emphasis on acoustic signalling, and Kirschbaum (1987) with an emphasis on reproductive biology. A more detailed analysis of the behavioral context in which electrical displays occur before and during courtship and spawning was needed for our study (summary time table, Fig. 13). Kirschbaum $(1984,1987)$ 

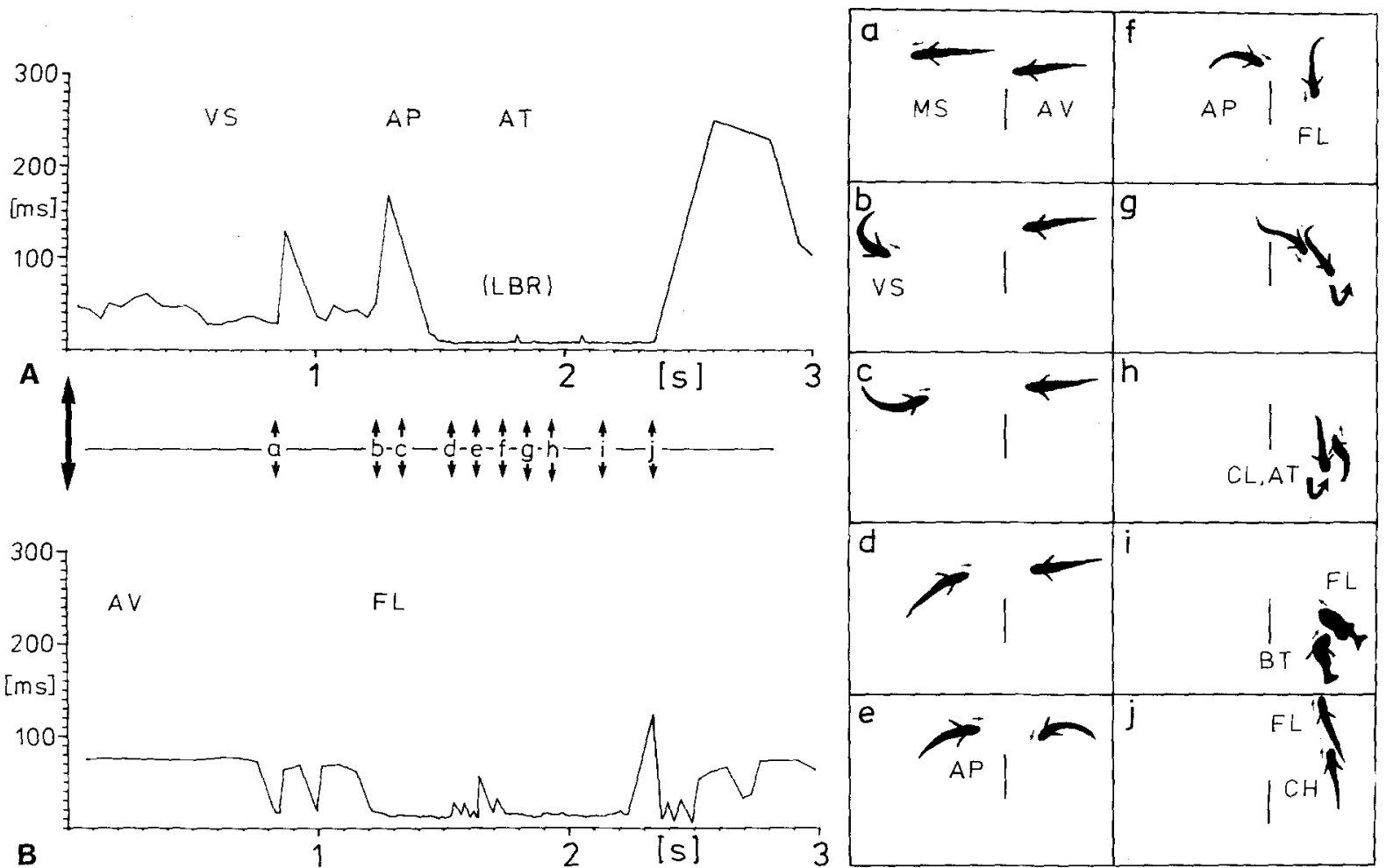

Fig. 2. A EOD activity of a male attacking $(A T)$ another male whose concurrent EOD is shown in $\mathbf{B}$, synchronized with video frames (a-j) recorded from underneath during daylight phase. Fish in $\mathbf{A}$ is to the left in $\mathbf{a}$, below in $\mathbf{j}$. (Bar $=5 \mathrm{~cm}$ reference in tank). $V S$ : vigorous swimming, $F L$ : fleeing, $M S$ : moderate swimming, $A V$ : avoidance, $A P$ : approach, $C L$ : circling, $B T$ : immediately before bite, $C H$ : chase, $L B R$ : long burst (mean interval: $8.3 \pm 1.7 \mathrm{~ms}, n=104$ burst intervals). Axes as in Fig. 1 (left)

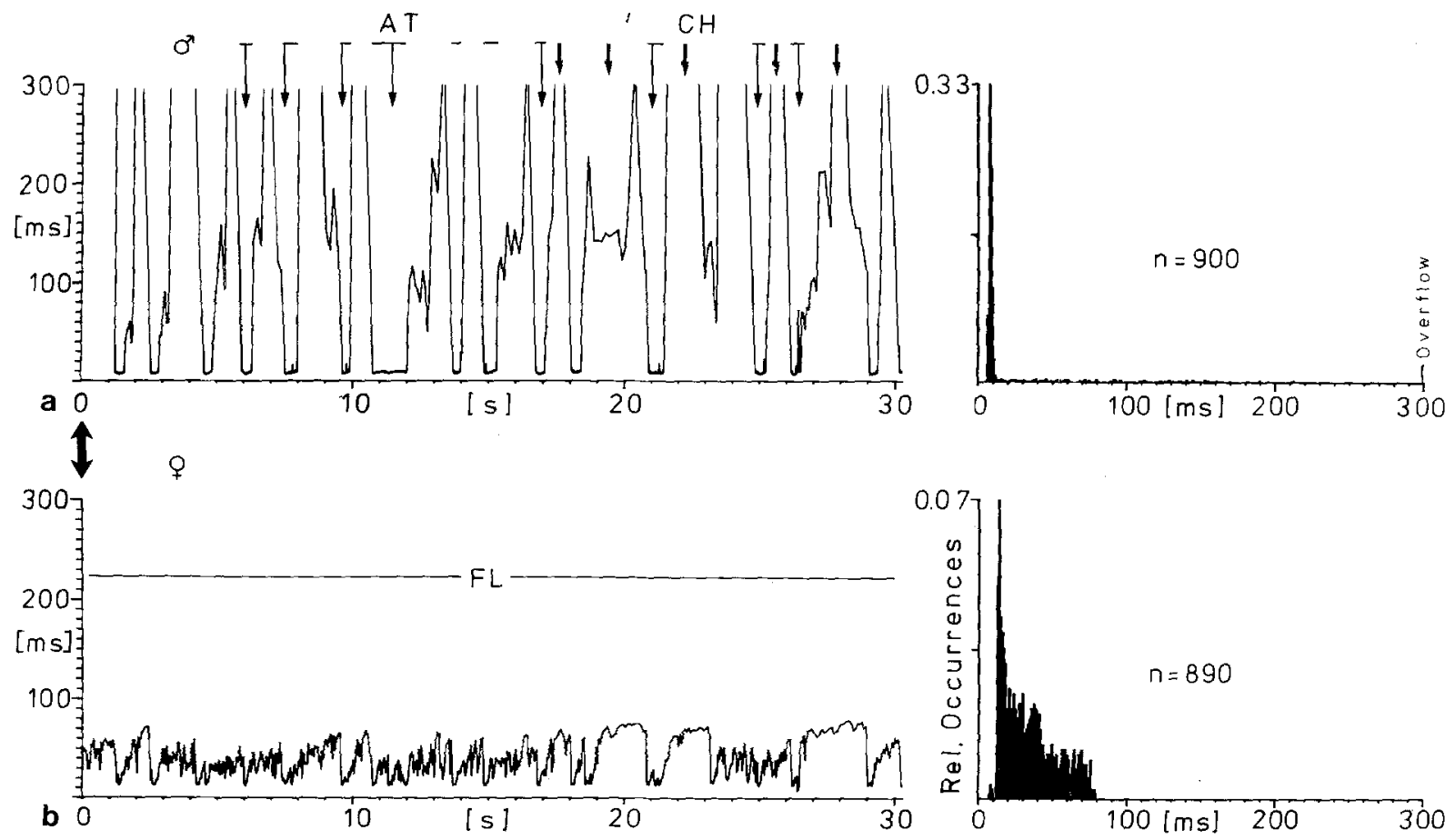

Fig. 3a, b. Concurrent interval patterns while (a) a male repeatedly attacked $(A T)$ and chased $(C H)$ (b) a female flceing $(F L$; mean interval: $33 \pm 18 \mathrm{~ms}$ ). Attack bursts: mean interval $8.5 \pm 1.3 \mathrm{~ms}, n=760$; Histograms on the right represent data to their left. Axes as in Fig. 1. Recorded during the daylight period 
has not studied electrical signalling, while Crawford et al. (1986) could not find any courtship-specific electrical behavior except a "cessation of the electric organ during vocalization".

One pair of our fish spawned 21 times in a 1201 breeding tank (tank I) of which 17 spawnings were recorded (EOD, song and behavior). In a second tank (tank II ; 360 1) a male failed to spawn with 2 females but later succeeded with two different females ( 5 spawnings). A third tank (tank III; 3601 ), incompletely divided by a glass partition, had one female paired with two males both building nests $(8$ spawnings with one male, 1 with the other male). Total number of spawning fish was 4 males and 4 females with 37 spawnings combined. Spawning began 4 to 6 weeks from the beginning of lowered conductivity but one pair spawned within one week of entry into a tank without changing conditions $(100 \mu \mathrm{S} / \mathrm{cm}$ in home and breeding tank).
Pre-spawning behavior. Within a day after the pairs were established, males began to dominate most of the bottom tank region. The female was usually excluded from all but the region near the surface, where she was able to hide in the floating plants or in a suspended hiding tube. Signs of being constantly attacked by the male appeared on the female as bites to the caudal and dorsal fins and scrapes to the body. Males mostly remained in or very near their hiding tube during daylight but constantly patrolled their territories during darkness. Females remained principally in their surface tubes during the day, but advanced repeatedly into the male's territory during the first few hours of darkness for food. The male was already producing his song during this stage (see later section).

The males began building nests several days to weeks before spawning occurred. Nest sites were typically built between rocks and pieces of pottery or within porous tubes, or even within their own

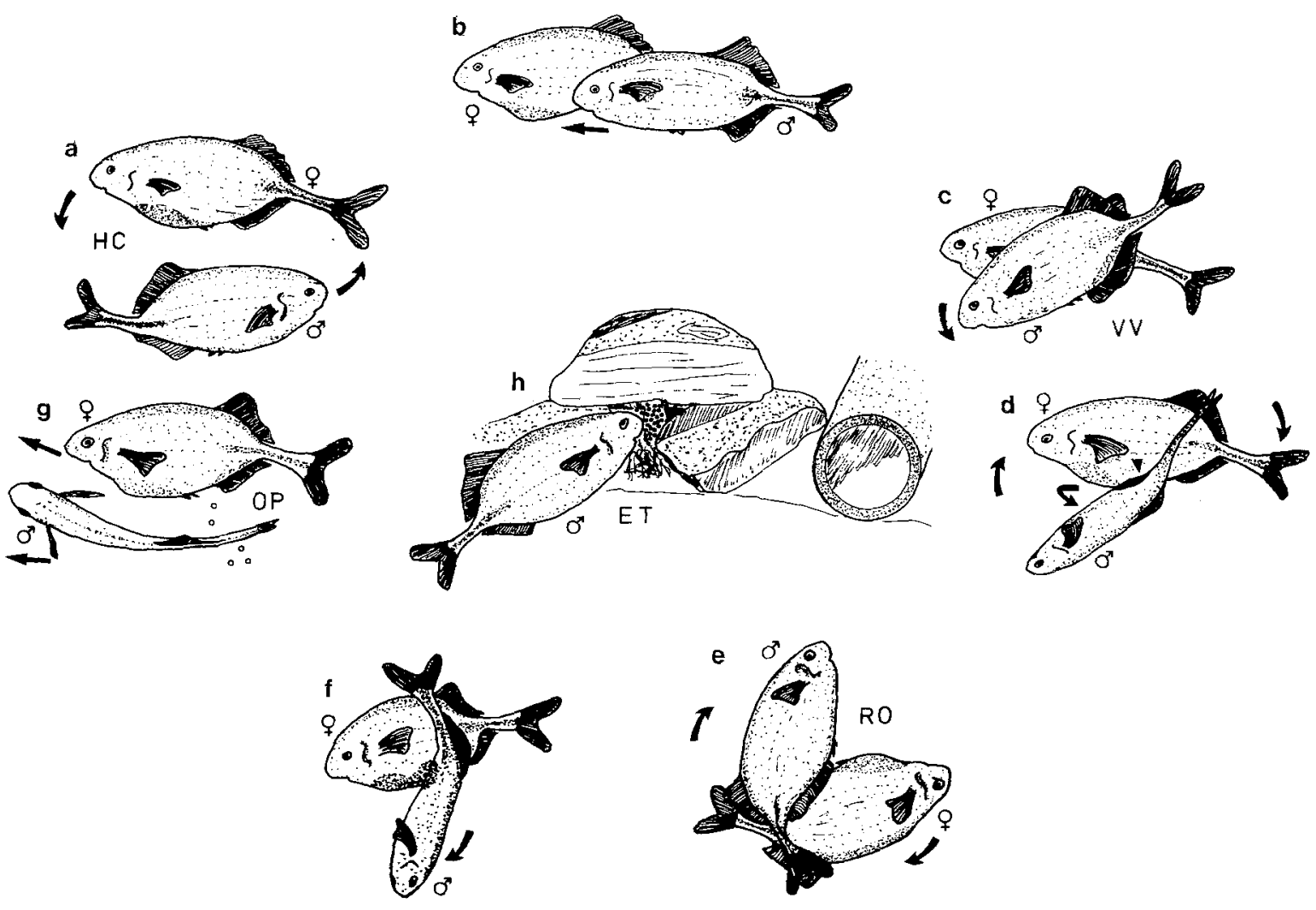

Fig. 4a-h. Sketch of the courtship and spawning behaviors drawn from infrared video recordings. During courtship (a-f) the male approaches the female and (a) Head-to-tail Circling $(H C)$ occurs. b The male arrives alongside of the stationary female, c becomes coupled Vent-to-Vent ( $V V)$, $\mathbf{d}$ then turns laterally, e as both fish pivot around each other, $\mathbf{f}$ in one complete Rotation $(R O)$. The male then separates and swims away followed by the female. During spawning the rotation is deleted and the sequence runs from (d) to (g) when the eggs are laid $(O P)$. The male then quickly picks up the eggs $(E T)$ in his mouth and (h) places them into the nest 
hiding tubes, but not burrowed into the substrate. Material for the nest consisted of "Java-moss" (Vesicularia dubyana) and other loose vegetation which the male picked up in his mouth and transported to the nest at night. Males formed the nest by a boring or nudging action into the nest material but did not tunnel or glue the nest. Nests were approximately $3 \times 3 \mathrm{~cm}$ wide and $4 \mathrm{~cm}$ deep depending on their placement. A nest built in a porous tube filled half its length (nest $7-9 \mathrm{~cm}$ long) and could be built in one evening. It was not uncommon for the male to construct a second nest or disassemble a disturbed one. In all three tanks the nest was always within $20-30 \mathrm{~cm}$ of the male's hiding tube. When spawning occurred more frequently than 18 days apart, a second nest was built for the eggs, otherwise males showed one preferred location for their nest.

Courtship. Courtship behavior (Fig. 4) began soon after darkness. The male, having already built a nest days before, patrolled his territory while searching for more nest materials, nudging the nest and foraging for food. The female advanced into the male's region from her surface tube or floating plants, but retreated quickly without contact with the male. Initially the male chased the female from his territory, nevertheless the female repeatedly returned as male aggression decreased over a period of 60 min from 10-20 attacks in the first hour to less than 4 per hour, allowing the female to enter the region near his hiding tube and nest.

Courtship began when the female swam to a location near the male's bottom hiding place (or into his hiding tube) and waited from 1 to $3 \mathrm{~s}$. The two fish circled several times (Head-to-tail Circling: HC; Fig. 4a) before the male was able to approach from behind ( $2-5 \mathrm{~s})$ and position himself laterally to the female (Fig. $4 \mathrm{~b}$; see also Crawford et al. 1986). The male then pitched head downward $20^{\circ}$ to $40^{\circ}$ to the female (Fig. $4 \mathrm{c}$ ) and quickly rolled $90^{\circ}$ to her side while both fish became tightly bound ventrally near the rostral edge of the anal fin (referred to as vent-to-vent coupling by Crawford et al. 1986; and in Fig. 4d). The female was pushed upward as both moved their caudal fins. This caused them to pivot around each other in one full oblique rotation while remaining coupled ventrally (Fig. $4 \mathrm{e}, \mathrm{f}$ ). A strong quivering movement of the caudal section accompanied the male's rotation during this stimulation. After completing one rotation $(3-4 \mathrm{~s})$, the fish separated and both swam away to their home regions. The rotation could be clockwise or anticlockwise (when viewed from above), but tended to be the same for any one spawning evening and perhaps partially depended on surrounding objects and plants.

The period of Head-to-tail Circling was circumvented when the male and female aligned correctly. The total courtship period lasted from 1 to $5 \mathrm{~h}$ when it preceded spawning, but could also occur without leading to spawning, especially 3 to 4 nights prior to the evening of spawning or less.

Spawning. Spawning immediately followed courtship and usually occurred in the same place. The female arrived first at the site (Female spawning Site wait: FS). The male then approached from behind without circling and rapidly positioned himself obliquely to the female's ventral side (Fig. 4c). He quickly rolled sideways while forcing the female upward slightly and stimulated her with a quivering action (Fig. $4 \mathrm{~d}$ ). This behavior normally lasted 2 to $4 \mathrm{~s}$ during which time the eggs were laid (Fig. $4 \mathrm{~g}$ ), fertilized and dropped to the bottom of the tank (1 to $3 \mathrm{~s}$ for Oviposition). Close up video recordings did not permit the observation of an anal fin reflex of the male during Vent-toVent behavior as reported by Kirschbaum (1987).

The male swam away first followed immediately by the female returning to her hiding place at the surface. The female showed a characteristic caudal Quivering motion during the first few $\mathrm{cm}$ of this Return (QR, lasting 1-2 s), absent during courtship. After swimming away the male quickly returned to the spawning site and searched for the eggs, picking up as many as 4 at a time in his mouth, and transferred them to the nest (Fig. 4h). The average time the female spent in the male's region for one spawning bout was $13 \pm 7 \mathrm{~s}(n=19)$ followed by wait periods in her home territory of 30 to $60 \mathrm{~s}$; the average duration of one complete spawning cycle was $72 \pm 45 \mathrm{~s}(n=16)$ interrupted by infrequent attacks by the male (1-3 per $h$ ).

Spawning continued for 2 to $6 \mathrm{~h}$ typically starting 2 to $5 \mathrm{~h}$ after dark and produced 50 to 192 eggs. The average number of eggs in tank I was $128 \pm 36$ in 9 spawnings; tank III : $127 \pm 25$ eggs in 9 spawnings. Attacks on females were usually less than 5 for the entire spawning period of a night. Pair formation was restricted to the period of courtship and spawning.

Post spawning behaviors. Following the conclusion of spawning the male tended to the nest, continued to search for eggs and covered the front of the nest with plant material (territory patrolling). The male's aggressiveness toward the female returned immediately (over 12 attacks per hour). The male remained near the nest during daylight and con- 
stantly checked the eggs during the first two weeks (nest nudging), but did not show any distinct nest fanning. Males cared for the eggs or young from different spawnings in the same nest or maintained two nests simultaneously. For the development of the fry, their larval discharge, and the male's brood caring behavior, see Kirschbaum (1977), Westby and Kirschbaum (1977, 1978), and Kirschbaum (1987); behavioral and some developmental aspects confirmed by our own observations.

Over a period of 384 days the mean spawning cycle was $24 \pm 20$ days with periods ranging from 6-71 days between spawning in tank I (tank III: $9.8 \pm 3.4$ days in 8 spawnings).

\section{EOD interval patterns during courtship and spawning}

Courtship EOD patterns. No pre-courtship EOD patterns of the male or female were observed that could predict spawning, even during the early period of the dark-phase on a spawning evening. Precourtship includes such patterns as already described above for resting, hiding, swimming, and aggression, for example, the resting interval histogram of a female at rest in her surface hiding region $(f=13.4 \mathrm{~Hz}$, bimodal at $11 \mathrm{~ms}$ and $100 \mathrm{~ms})$. This pattern (Medium Sporadic Rate) contained many short bursts (mean: $18 \pm 9$ bursts/min, 3 females; see Fig. 5a). The male concurrently displayed a High Sporadic Rate $(f=18.3 \mathrm{~Hz}$, unimodal) swimming pattern (broad mode centered on $37 \mathrm{~ms}$; 3 males) without bursts. During this time the male was actively patrolling his bottom territory for food, nest materials and excluding intruders.

On spawning nights, however, the female began a very stable unique discharge pattern, consisting of nearly equal intervals centered on $100 \mathrm{~ms}$, beginning in the first few hours of the dark-phase, while resting in her home region (4-13 s in Fig. 5b; Medium Uniform Rate). The interval histogram showed a narrow, single mode with its peak between 80 and $130 \mathrm{~ms}$ but differing among spawning nights (Fig. 6). This EOD pattern of courtship was completely devoid of short bursts, except during attacks by the male; it continued through the whole courtship and spawning period. This persistance distinguishes the courtship pattern from the similar hovering and avoidance patterns of nonreproductive behaviors which normally lasted only 20 to $60 \mathrm{~s}$. Unlike the hovering and avoidance patterns the courtship pattern was not provoked by aggressive behaviors from the male, but rather followed from the earlier period of normal resting and hiding.
Table 2. A catalogue of electric organ discharge patterns (and pattern elements) correlated with overt social behaviors. EOD interval ranges in $\mathrm{ms}$; mean $\mathrm{EOD}$ rates in $\mathrm{Hz}$

\section{Discharge cessations}

Discharge Break (300 ms-1 s silence)

(PR, HD, CH, ET, CA, male-VV)

Discharge Arrest ( $>1 \mathrm{~s}$ silence)

(HV, AV, FS, OP, QR, FL, CH)

[DBR]

[DAR]

Tonic discharge

Low Uniform Rate sequence (300-800 ms; $1.3-3.3 \mathrm{~Hz})(9-12 \mathrm{~d} \text { old juvenile fish })^{a}$

Medium Uniform Rate sequence $(80-300 \mathrm{~ms}$; $3.3-12.5 \mathrm{~Hz}$ ) (HV, SS, CP, AV, FW, male-VV)

High Uniform Rate sequence $(20-80 \mathrm{~ms}$; 12.5-50.0 Hz) (VS, FL)

Low Sporadic Rate sequence $(300-800 \mathrm{~ms}$; 1.3-3.3 Hz) (female FS-VV-OP; $20-80 \mathrm{~d}$ old juvenile fish ${ }^{\mathrm{a}}$

Medium Sporadic Rate sequence ( $80-300 \mathrm{~ms}$; $3.3-12.5 \mathrm{~Hz}$ ) (RM, NN, female-FS and VV)

High Sporadic Rate sequence $(20-80 \mathrm{~ms}$; $12.5-50.0 \mathrm{~Hz}$ ) (SS, MS, VS, PR, FL, AP, $\mathrm{TP}, \mathrm{ET}, \mathrm{NN}$ )

[MUR]

[HUR]

[MSR]

[HSR]

\section{Patterned frequency modulations}

Short Burst ( $<20$ intervals, 8-12 ms length) (RM, ES)

Long Burst ( $>20$ intervals) (AT, BT, AP, CA)

[SBR]

Maximum species rate (8-11 ms; $91-125 \mathrm{~Hz}$ in bursts) [MAX] (RM, AT, BT, CA, AP, ES)

Short Rise (rapid acceleration)

(AV, AP, BT, NN, PR)

Long Rise (slow acceleration) (RM, HD)

Smooth Decelerations (long decrease)

(HV, TP, HD)

Intermittent pattern (many pauses) (part of PR, female-VV-FS-OP-QR)

Regular Alternation (of high and low rate; see Fig. 10) (female HD, ES, following

CA by male in courtship)

Displays involving paired fish

Preferred Latency Response (echo) (male RM) ${ }^{\text {b }}$

Preferred Latency Avoidance (female toward stimulus or heterospecific fish) ${ }^{b}$

Synchronization (same MUR between 2 fish) (HD, HV)

[SRS]

[LRS]

[SDC]

[INT]

[RAL]

${ }^{a}$ see Westby and Kirschbaum 1977; and personal observations

b Kramer 1978; Lücker and Kramer 1981

Male Courtship Attacks (CA in Fig. 5b) involved long bursts directed toward the female hiding in her tube or in surface plants and was followed by a Moan-Grunt-Growl sequence of his song (see below). The female continued the Medium Uniform Rate pattern while the male patrolled his region.

When the female swam into the male's territory without discharging the male switched from his Territory-EOD pattern to a Medium Uniform 

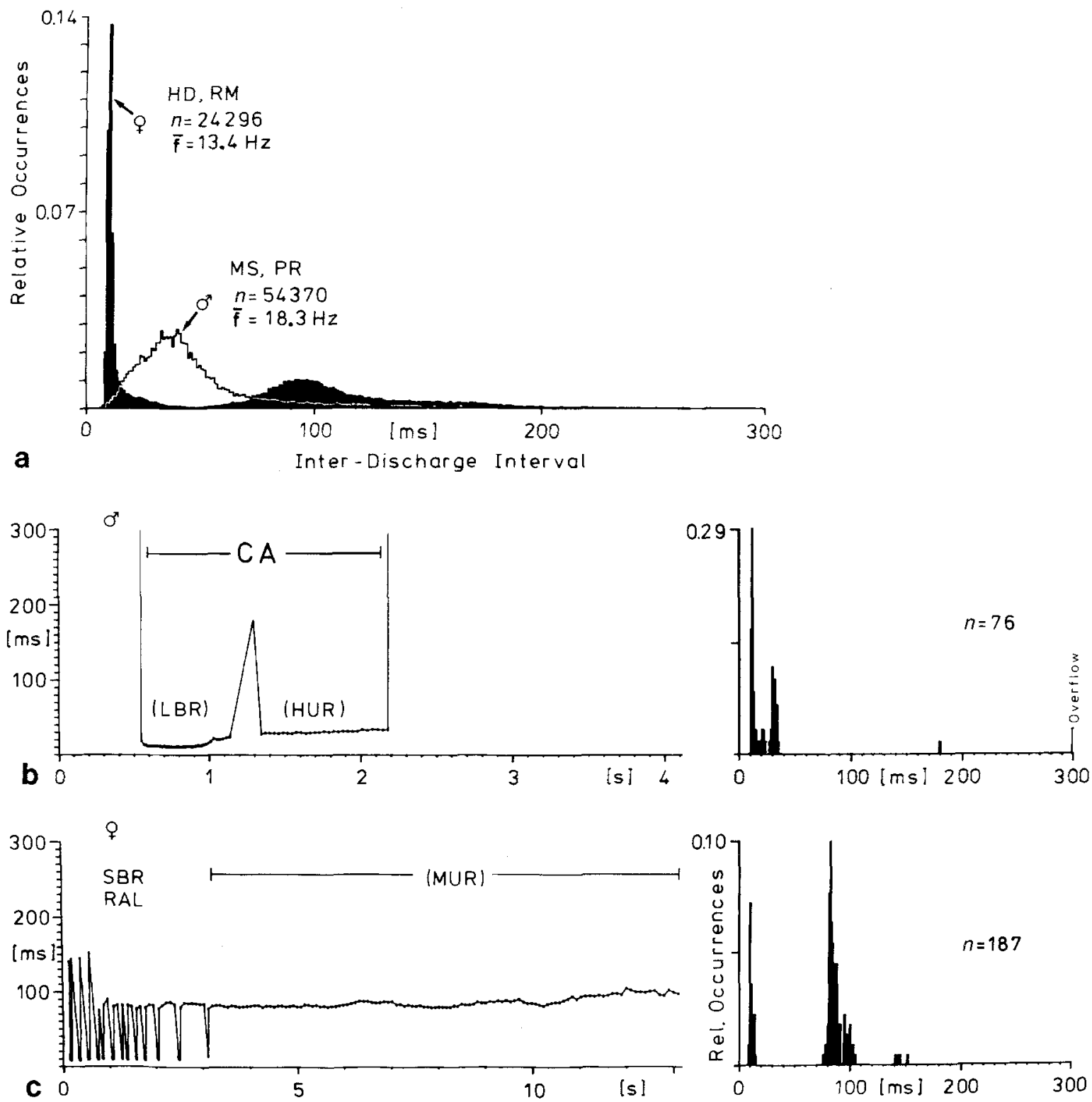

Fig. 5a-c. Male and female EOD displays preceding courtship. Axes: as in Fig. 1. a Inter-discharge interval histograms recorded from a female (black histogram) Resting and Hiding $(R M, H D)$ in her territory, and from a male (white histogram) Swimming and Probing $(M S, P R)$ in his region of the same tank. Concurrent recording during the first 90 min of darkness, 5 days before spawning. $n=$ number of EOD intervals; $\bar{f}=$ mean EOD rate in Hz. b, c Male and female patterns occurring during beginning courtship (not concurrent). b Male Courtship Attack $(C A)$ accompanied by a Long Burst ( $L B R$; mean interval: $12.3 \pm 1.8 \mathrm{~ms}$, $n=39$ ) and High Uniform Rate (HUR; mean interval: $30.6 \pm 2.6 \mathrm{~ms}, n=30$ ) directed toward the female hiding in her tube. c The female's Regular Alternation $(R A L)$ of low and high discharge rate $(S B R$; mean burst interval: $11.1 \pm 1.6 \mathrm{~ms}, n=42)$ after such an attack by the male (first $3 \mathrm{~s}$ of this record) changing into the female courtship pattern of a Medium Uniform Rate (MUR; mean interval: $86 \pm 6 \mathrm{~ms}, n=141$ ). Histograms on the right represent data to their left

Rate (Fig. 7). While going through the courtship ritual of Head-to-tail Circling, Vent-to-Vent coupling and Rotation the female displayed a Low to Medium Sporadic Rate with Discharge Breaks; the male continued his Medium Uniform Rate except for a Discharge Arrest during Vent-to-Vent coupling, also observed later when spawning. The low EOD rates accompanying the rather vigorous motor behavior of Head-to-tail Circling were surprising.

On the female's electrically silent (or almost silent) return to her home region the male switched back to Territory Patrolling and the associated High Sporadic Rate. 

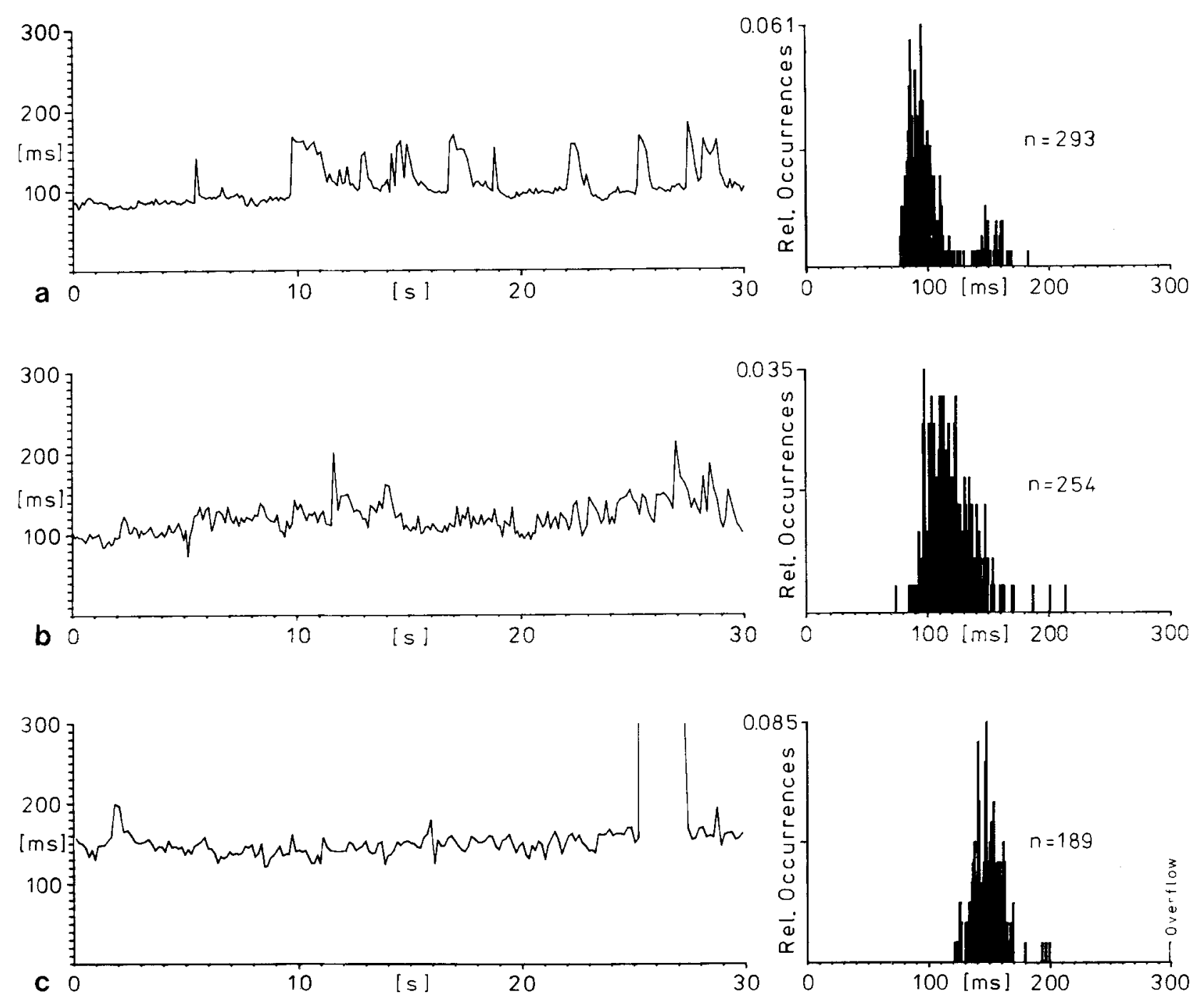

Fig. 6a-c. Three examples of the same female's courtship pattern of a Medium Uniform Rate on different spawning evenings. Note that histogram peaks range from 85 to $145 \mathrm{~ms}$. Axes as in Fig. 1

Spawning EOD patterns. Males continued to display a swimming-probing pattern (Medium Sporadic Rate) while the female remained in her own region. The electrical displays of both fish during a spawning bout were very similar to those they had shown during the courtship ritual. The male changed his EOD pattern (High to Medium Sporadic Rate) to a Medium Uniform Rate (MUR in Fig. 8a; further examples in Fig. 9) just as the female entered his territory; this pattern continued throughout the spawning behaviors of Female spawning site Wait, Oviposition and Quiver Return. This Medium Uniform Rate pattern was only briefly interrupted by a Discharge Break observed during Vent-to-Vent coupling; independent of whether it occurred during courtship or spawning.
During spawning he displayed 1 to 3 long intervals (mean: $272 \pm 71 \mathrm{~ms}, n=37$ ).

The female showed a Low Sporadic Rate with Discharge Arrests when at the spawning site and during her travel to and from the site (Fig. 8). On resuming discharging after her silent return to her home site, the male immediately switched back from his Medium Uniform Rate to an Egg-Transport/Territory-Patrolling pattern, reflecting his heightened activities of Egg Transport and Territory Patrolling between spawning bouts (Fig. 8). The female displayed her original Medium Uniform Rate while waiting in her territory (FW in Fig. 8).

The same sequencing of patterns were seen on all 17 recorded spawnings in tank I (Fig. 8) and also observed in tanks II and III. The male pattern 


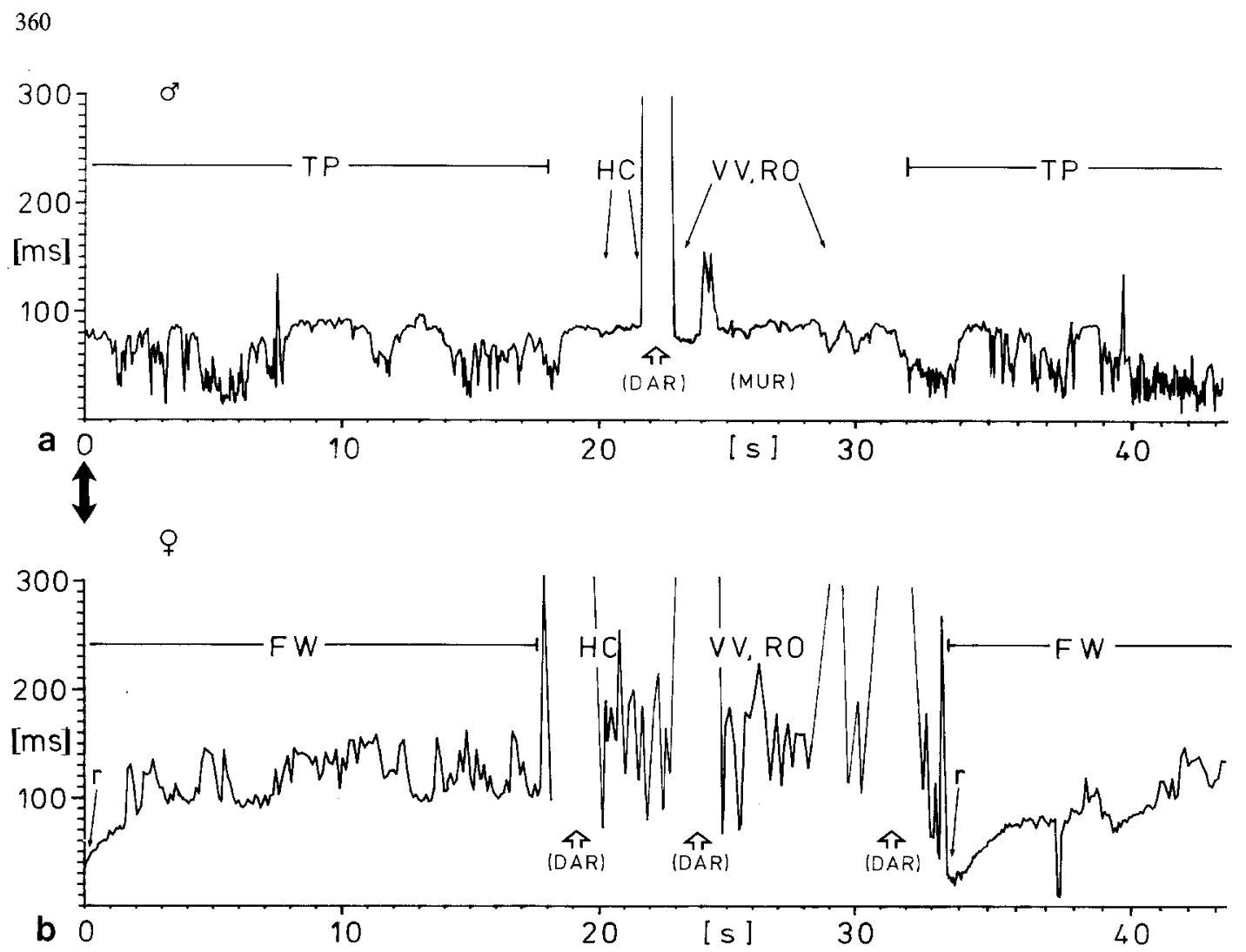

Fig. 7a, b. Concurrent EOD intervals during one courtship bout of (a) the male and (b) female. Record begins with the male Patrolling his Territory $(T P)$ while the Female Waits $(F W)$ in her tube (first $18 \mathrm{~s}$ ). The male EOD pattern of a Medium Uniform Rate $(M U R)$ continues through Head-to-tail Circling $(H C)$, Vent-to-Vent coupling $(V V)$ and Rotation $(R O)$, only interrupted by a Discharge Arrest $(D A R)$ during Vent-to-Vent coupling. On arrival at the courtship site (beginning at $20 \mathrm{~s}$ ) the female displayed a Low to Medium Sporadic Rate with many Discharge Arrests $(D A R)$ before returning to her tube (' $r$ ' at $34 \mathrm{~s}$ ). Abscissa: time (in seconds); ordinate: length of each inter-EOD interval (in ms)

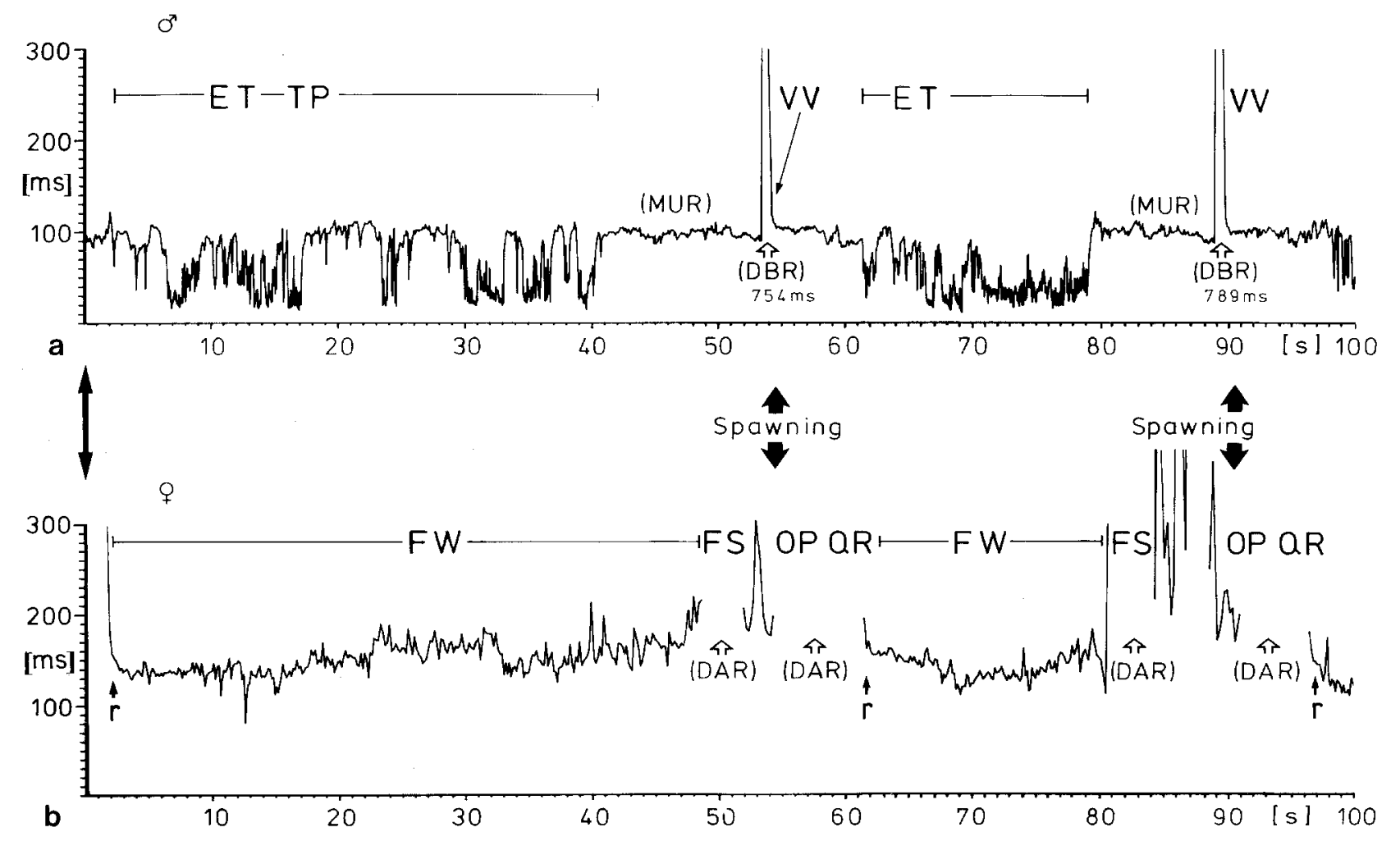



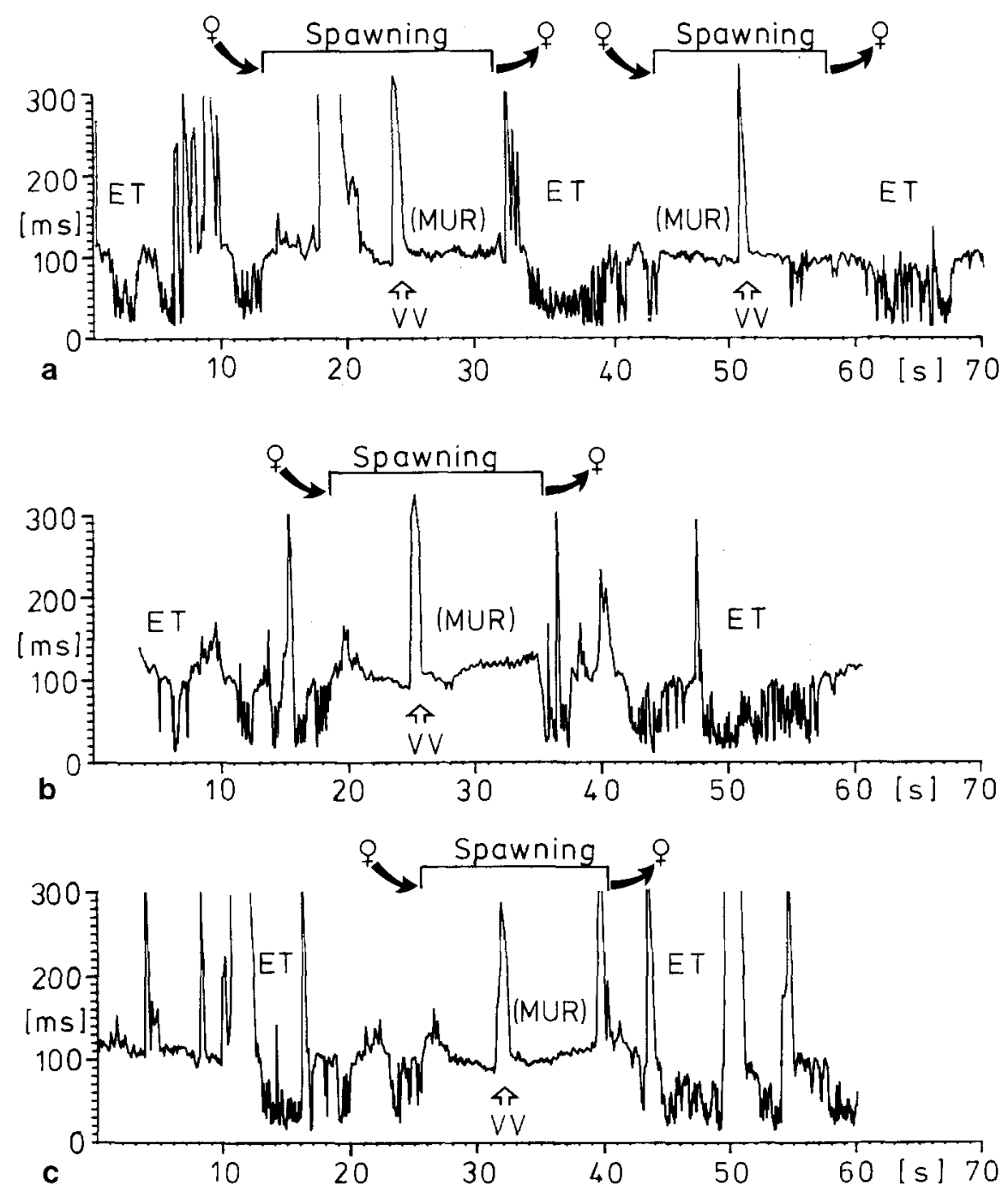

Fig. 9. Three examples of the male spawning patterns from Egg Transport $(E T)$ through the spawning sequence. Note that during Vent-to-Vent coupling $(V V)$ the male's Medium Uniform Rate $(M U R)$ pattern is interrupted by a Discharge Break typically of three long intervals (average: $272 \pm 71 \mathrm{~ms}, n=37$ ). Female entry and exit into male region is indicated above. Axes as in Fig. 7 of Medium Uniform Rate, while at the spawning site with the female, was characteristic of this behavior. The exact time of onset of the male's Medium Uniform Rate varied with respect to the female's arrival at the spawning site. Part of the time she would arrive after he had begun the Medium Uniform Rate pattern and spawning would proceed smoothly. When she arrived before the onset of the male's uniform rate, he often attacked her or failed to get into correct Vent-to-Vent position.

At the completion of spawning, and without disturbances from the male, the female began dis- playing a pattern with many rapidly recurring Short Bursts while remaining in her region (Fig. 10b). This had also been seen during some of the courtship and spawning attacks $(0-3 \mathrm{~s}$ in Fig. 5c). These regular alternations of long intervals with bursts were only found to occur in the female.

Preferred Latency Responses (PLR, PLA). The Preferred Latency Response (PLR) of male and the Preferred Latency Avoidance (PLA) of female $P$. isidor $i$ are sex specific and only observed in ma-

Fig. 8a, b. Concurrent EOD intervals during two spawning bouts of (a) the male and (b) female. Record begins with the female just returning to her tube (' $r$ ) and waiting $(F W)$, and the male patrolling within his territory $(T P$, ET). Note that the male and female spawning patterns closely resemble those observed during courtship (Fig. 7). A Discharge Break $(D B R)$ of the male occurred during Vent-to-Vent coupling $(V V)$; the female arrests her discharge $(D A R)$ during part of the spawning sequence. ET: Egg Transport, FS: Female Spawning site wait for male, $O P$ : Oviposition, $Q R$ : female Quiver Return to home region. Other abbreviations and axes as in Fig. 7 


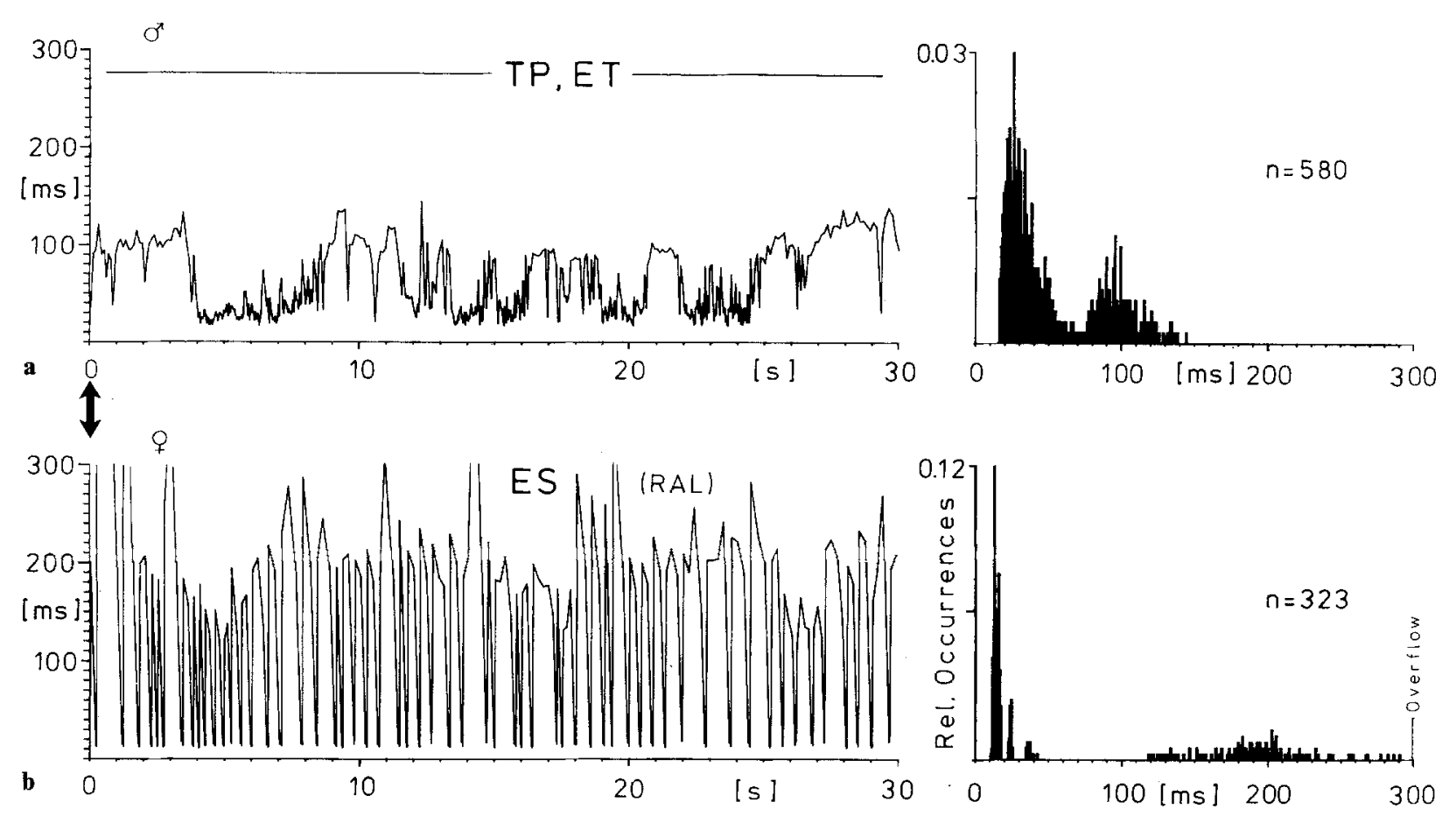

Fig. 10a, b. Concurrent interval patterns from the end of spawning. a Male tending to the nest and searching for the remaining eggs (TP, ET; average interval: $52 \pm 33 \mathrm{~ms}$ ). b Regularly repeated (RAL) short bursts by the female (1.93 bursts per second; average EOD interval during bursts: $14 \pm 1.8 \mathrm{~ms}, n=156$ ) that occurred at the completion of spawning. Histograms on the right represent data to their left. Axes as in Fig. 1

ture fish (Kramer 1978; Lücker and Kramer 1981). From the 8 spawning fish of the present study (4 males, 4 females), all males displayed a PLR while 3 females displayed PLA (no data on one) when stimulated with a dipole.

Because of the short range of the latency response ( $\leq$ about $20 \mathrm{~cm}$ in G. petersii; Russell et al. 1974) fish were only examined when separated by less than $30 \mathrm{~cm}$. The effective range for the PLR/ PLA in $P$. isidori probably is still shorter than that of $G$. petersii because its EOD amplitude is much weaker (by a factor of $>10$; see Kramer 1974, 1978).

Synchronized recordings from 84 pairs including all behaviors and EOD patterns in Tables 1 and 2 were examined. The Preferred Latency Response did not occur during any of the hovering, aggression, courtship, or spawning patterns (also in $G$. petersii, the PLR was not observed during attacks; Kramer 1974). The strongest situations for latency responses between two fish were during the interval patterns of hiding and resting. Males responded to nearby females with preferred latencies of 12-16 ms irrespective of whether in experimental tanks devoid of plants or rocks (EOD separation by wire method), or in spawning tanks with the females hiding in the surface plant layer near the male's tube. The response did not continue to occur under these situations, but rather was present during the first few hours of enter of a female into the tank of an established male. "Wired" males introduced into an experimental tank showed PLR as did established males in spawning or experimental tanks when a female was introduced.

Females did not show the Preferred Latency Avoidance during any of the situations that were recorded although they did display the response towards an 8-10 Hz stimulus dipole (see Methods). Kramer (1978) observed spontaneous PLA behavior between two fish. The reason for this discrepancy could be insufficient stimulus amplitude in the present study (see above).

\section{EOD waveform variability}

Intraspecific EOD waveform variability in $P$. isidori is dealt with in Lücker and Kramer (1981), Westby and Kirschbaum (1982), and Bratton and Kramer (1988). Therefore, we need only add here that successful courtship and spawning (11 spawnings between two males) occurred with a female that had a "male-typical" EOD waveform according to Westby and Kirschbaum (1982) (P1/P2-ra- 
tio $=0.75$; see Bratton and Kramer 1988). Another female whose EOD had a spectral peak amplitude lower than the male average (below $13.4 \mathrm{kHz}$ ) also spawned successfully.

\section{Sound production of the male}

Occurring during the time of territorial establishment, the male $P$. isidori produced an acoustic song. Absent during most of the daylight hours the male began singing at the beginning of darkness regardless of whether or not he had built a nest. The male sang less during the early stages of courtship and was silent for the courtship and spawning period, except for infrequent courtship attacks when he sang for short periods $(<10 \mathrm{~s}$; 19 spawnings in 2 tanks).

a
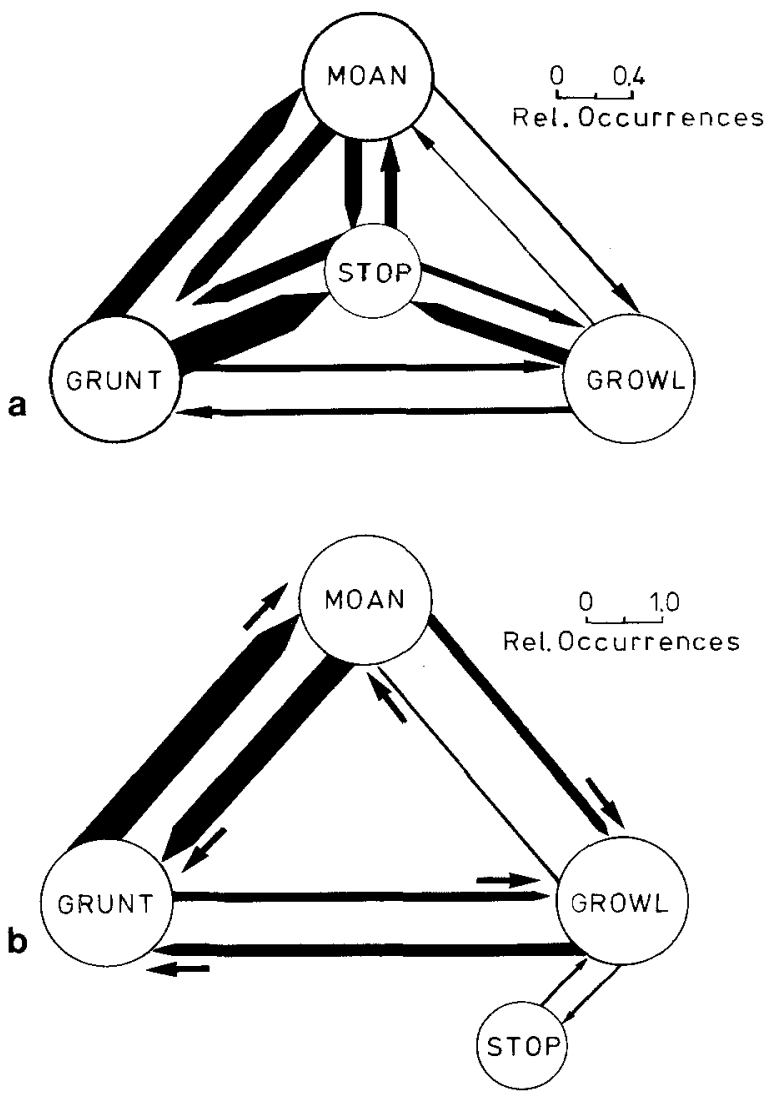

Fig. 11 a, b. Transition diagram of the elements of the male acoustic song. a Song on a non-courtship/spawning night with many stops (silence). Total transitions $=204 ; 420 \mathrm{~s}$ sample; song time $=610 \mathrm{~s}$. b Nearly continuous song ( $355 \mathrm{~s}$ sample; song time $=333 \mathrm{~s}$ ) which followed the end of spawning. The male was again patrolling his territory with the female remaining in her surface region. Song consisted of growls $(52 \%$ of total time, $n=56$ ), moans (34\% of time, $n=104$ ) and grunts $(9 \%$ of time, $n=120$ ). Most of the transitions were between moans and grunts
As recently described by Crawford et al. (1986) there are three distinct sounds that the male produces: 1) Moan, 2) Grunt and 3) Growl during courtship and two sounds during aggression, 4) Hoot and 5) Pop. Only the first three pertain to the courtship behavior of this species. Our recordings of these sounds were so similar to those of Crawford et al. (1986) that a redescription is unnecessary. We give statistical information about the sequence of song elements and their behavioral context from data on 3 spawning males here.

The male produced the moan, often the first element of a song sequence when near or within his hiding tube or close to the nest. He was usually not swimming vigorously but rather sang as a reaction to the female when she entered his territory during precourtship and early courtship. Moans were the most common element $(30-70 \%$ of total song time; from a $353 \mathrm{~s}$ sample at the end of spawning) being interrupted by grunts and often merged with the growl (Fig. 11).

The grunt (250-300 ms long; $9-15 \%$ of song time) occurred between other elements such as the moan. The sharp grunt or snort sound usually followed a long moan sequence or was interjected between short moans. The growl was the second most common sound in duration after moans (55\% of song time) and ranged from $0.5-12 \mathrm{~s}$ (mean: $3.3 \pm 2.9 \mathrm{~s}$ ). The growl often merged into or out of the moan which added to its waveform complexity in oscillographic and sonograph recordings. Moans were interrupted by sharp grunts. Growls were often the finishing element or led into the next sequence. The typical call of moan, grunt, moan often ended without a growl, or the growl followed a succession of moan-grunt-moans (Fig. 12).

The male pieced together the three elements (moan, growl, grunt) into a complex song that usually lasted as 3 to $10 \mathrm{~s}$ episodes followed by long pauses of silence. When the female was active intermittently in the male's region during pre-courtship, the male sang for longer periods of time (nearly continuously $50-90 \%$; lasting over $5 \mathrm{~min}$.

Female EOD interval patterns showed only an occasional reaction when the male grunted or growled but did not when he moaned (Fig. 12). Females did not hesitate to enter male territories during their calls, but would retreat quickly to her tube after a high amplitude grunt.

\section{Discussion}

In Pollimyrus isidori we find an amazingly complex behavior on at least three levels: the courtship and 

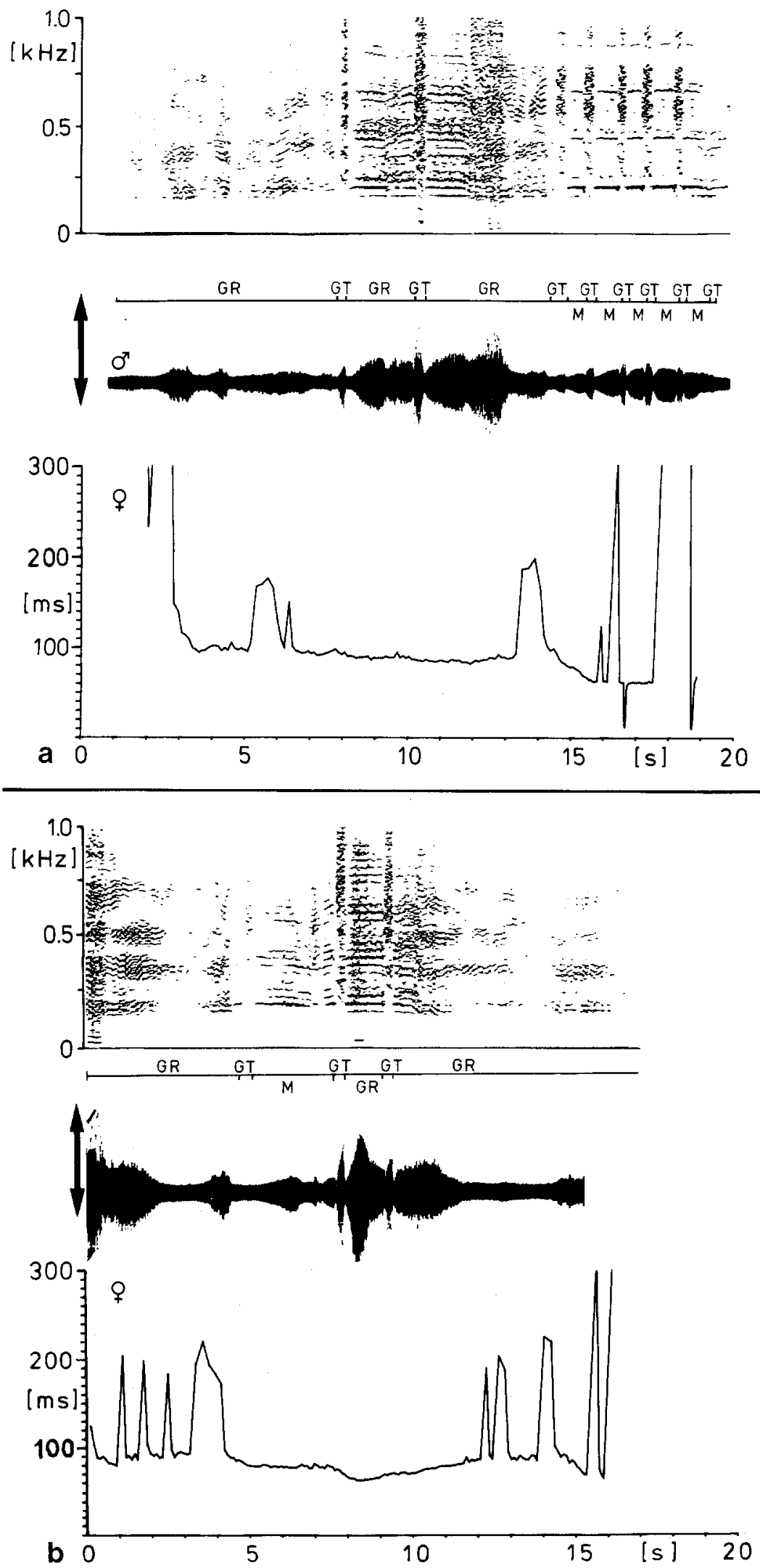

Fig. 12. Two examples of the concurrent EOD interval pattern of a female and the acoustical song of a male during early courtship. Female EOD while waiting in home region. $M$ : Moan, $G T$ : Grunt, GR: Growl. Sonograms: frequency of sound in $\mathrm{kHz}$; and oscillograms: sound pressure as detected with a hydrophone, are above the sequential EOD interval plot 


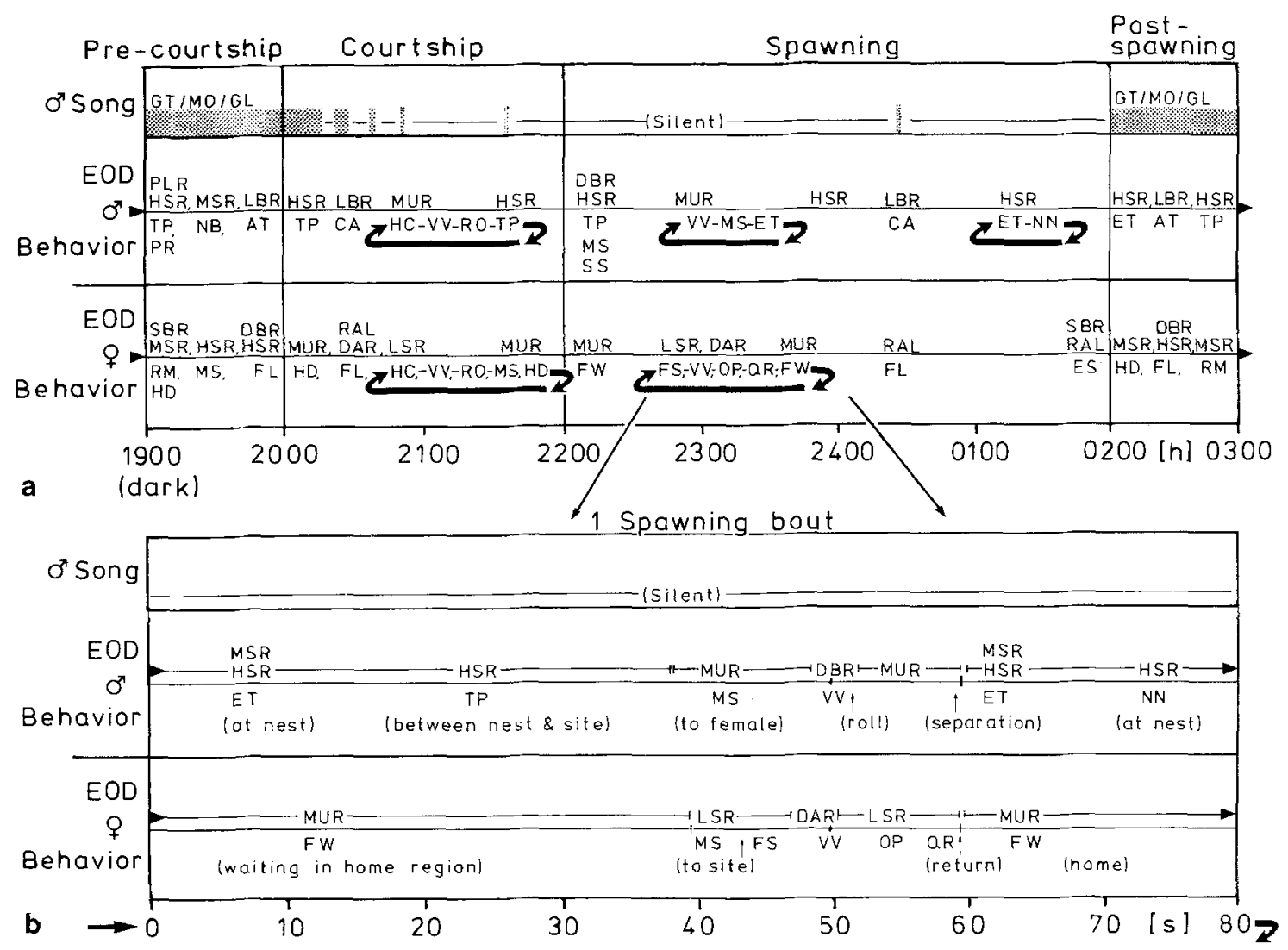

Fig. 13a, b. Summary time table showing the relationship of EOD, behavior and song during (a) the spawning night (lights out at $1900 \mathrm{~h}$ ) and (b) detail of one spawning bout as seen in Figs. 4 and 8 . See Table 1 and 2 for abbreviations

spawning ritual (Fig. 4 ; in part described by Crawford et al. 1986, and Kirschbaum 1987), the EOD activity accompanying all stages (Figs. 7-9), and the male's acoustic song (Crawford et al. 1986; confirmed by the present study). On each of these behavioral levels this small mormyrid seems to beat all records of complexity. Figure 13 presents an integrated summary time table.

Female and male EOD patterns leading up to and during spawning were the main concern of the present study. Both the resting type histogram of the female and the swimming histogram of the male observed before and between spawning nights, are examples of expected patterns for those specific behaviors (Figs. 1, 5a). Males are aggressive towards females (or any intruder) and swim to protect their territories. The females are displaced to the surface plant layer or hiding tubes and show a normal resting EOD interval pattern. Aggressively chased females displayed Discharge Arrests, or a Medium Uniform Rate (Fig. 3) which appeared to be important as an appeasement signal during Avoidance, reducing the number of attacks elicited by the dominant fish, or acting like a threat signal as presumed in G. petersii (Kramer 1976a).
Is there a message in the female's pattern that informs the male days or even weeks in advance to build a nest? This information may lie in behavioral encounters when fish are aggressive (Figs. 2, $3,5 \mathrm{~b}, \mathrm{c})$, or during the periods of first contact between mates when the sexually dimorphic latency response (Kramer 1978; Lücker and Kramer 1981) is shown (see Results). Some males came into breeding condition spontaneously and built nests without the presence of a female. Spawning males also failed to maintain nests with previously spawning females in the tank when, for extended periods of time, the female was not gravid (personal observation). Sex-specific features of the EOD waveform (as assumed by Westby and Kirschbaum 1982; but see Bratton and Kramer 1988) do not appear to be necessary for successful spawning, as shown by two of our females, one with a "male-typical" waveform, the other with a "male-typical" low peak of its EOD amplitude spectrum (see Results).

Regardless of which factors induce the male into nest building they do not decrease his aggression toward the female (Fig. 5b). This contrasts with the sharply decreased aggression on the even- 
ing of courtship and spawning. Males normally do not tolerate intrusion into their regions, including females. Counter to this, females were able to enter male territories for courtship and spawning; but then they were excluded once again at the End of Spawning. During early courtship females changed from a Medium Sporadic Rate to a steady uniform interval pattern around $8-12 \mathrm{~Hz}$, they also displayed throughout the whole spawning period (Figs. 7, 8, 13). This pattern was devoid of the short bursts prevalent during resting $(30-90 \mathrm{~min}$ before spawning; Fig. 5a), and differed from the similar Avoidance and Hovering patterns by its persistance and its occurrence in a context with no or little aggression. This then constituted the female spawning readiness pattern: a signal to males which are prepared with a territory and nest to allow the female into their region.

The male showed a typical swimming-probing discharge pattern until contact during courtship and spawning occurred (Fig. 5a). Typically preceding the female's visit by a few seconds, males displayed an EOD interval pattern of a Medium Uniform Rate (without bursts and very similar to the "spawning readiness pattern" of the female; Figs. 7, 8,9). As suggested by the relative timing, the female might normally wait for this EOD male pattern to occur before swimming to the spawning site and waiting for the male (Figs. 7-9). On the female's electrically silent return to her home site a close temporal correlation between her resuming discharging (Medium Uniform Rate during Female home Wait) and the male's change from a Medium Uniform Rate to an Egg-Transport/Territory-Patrolling pattern was regularly observed (Figs. 7-9).

Acoustic signals did not occur during femalemale engagement (courting and spawning) except for infrequent Courtship Attacks (Fig. 12); acoustic signals were never observed during Vent-toVent coupling. It was not clear why the male started singing again after the End of Spawning (after about 2:00 a.m. on a spawning night; see Fig. 13). One possible explanation is that he would continue to spawn with the same or any other female ready to mate. This would be compatible with a polygynous mating system which is probably present, let alone for the relatively heavy male investment (nest-building, territorial defense, broodcare; see Wilson 1975), and the resources the male holds (territory, nest; resource defense polygyny).

Why should their be this duality of acoustic and electric communication channels? We do not yet know how general acoustic communication is present within the Mormyridae, except for their good hearing (von Frisch 1938; Kramer et al. 1981; McCormick and Popper 1984) and sound production in $G$. petersii (Rigley and Marshall 1973). One reason for the continued or newly acquired capability of acoustic communication in addition to electric communication may be $P$. isidor$i$ 's weak EOD amplitude. Because of its physiology specialized to produce one of the shortest pulses known from any bioelectric source $(17-40 \mu$ s for the head-negative spike; see Bratton and Kramer 1988 ) the output of $P$. isidori's electric organ is much weaker than in $G$. petersii or $B$. niger of comparable size (see Kramer 1976b, 1978). The acoustic signal, which might propagate farther than $P$. isidori's weak electrical discharge, would serve well as an "advertisement call" (Crawford et al. 1986). Gravid females who supposedly do not hold territories could search out males that are established as indicated by their song. As apparent from our analyses the singing activity declines during early courtship and is completely absent during spawning (which may last for several hours); it is the EOD which continues to subserve communication between mates also during the critical stages of reproductive behavior.

\section{Conclusions}

EOD interval patterns probably play an important role in establishing sex identity and acceptance at the time of mating. The male EOD pattern, mostly comprised of swimming patterns (territory patrolling and nest building) is not sex specific; but such activity patterns along with the male acoustic song might attract the territory-lacking female who is ready for spawning.

The more subtle patterns of EOD phase-locking revealed during pre-spawning (PLR, PLA) may be essential for sex recognition and the courtship behavior to be initiated. We have not yet found this in our study of observed behaviors prior to courtship. A specific EOD rhythm (Medium Uniform Rate) informs the male of the presence of a gravid female, decreases his aggression towards her and allows her intrusions into his territory while he engages in a similar EOD pattern only when he is ready for courtship and spawning.

Considering the possible mechanisms of communication in $P$. isidori, social signalling for these fish probably involves a combination of channels. Context-specific EOD interval patterns of both partners prior to and during spawning are shown 
to form an integral part in the communication system of this species.

Acknowledgements. This work was supported by the Deutsche Forschungsgemeinschaft (SFB4/Teilprojekt H1). We wish to thank Drs. D. Burkhardt, H. Markl, and T. Szabo for critically discussing the manuscript. We are also grateful to D. Weymann for help and the construction of the electronic apparatus, to U. Heinrich for discussions and help, to Dr. U. Juergens (MPI für Psychiatrie, München) for help in producing the sonograms, and to B. Otto for assisting in many ways, including the care of the fish. A special thanks to Linda Cormick-Bratton for patient assistance with the manuscript, figures, proof reading, and rewrites. B.K. gratefully acknowledges F. Kirschbaum for introducing him into the spawning behavior of Pollimyrus isidori.

\section{References}

Bauer R (1972) High electrical discharge frequency during aggressive behaviour in a mormyrid fish, Gnathonemus petersii. Experientia 28:669-670

Bauer R (1974) Electric organ discharge activity of resting and stimulated Gnathonemus petersii (Mormyridae). Behaviour $50: 306-323$

Bauer R, Kramer B (1974) Agonistic behaviour in mormyrid fish: Latency-relationship between the electric discharges of Gnathonemus petersii and Mormyrus rume. Experientia $30: 51-52$

Belbenoit P (1970) Conditionnement instrumental de l'électroperception des objets chez Gnathonemus petersii (Mormyridae, Teleostei, Pisces). Z Vergl Physiol 67:192-204

Bell CC (1979) Central nervous system physiology of electroreception, a review. J Physiol (Paris) 75:361-379

Bell CC (1986) Electroreception in mormyrid fish: central physiology. In: Bullock TH, Heiligenberg W (eds) Electroreception. Wiley \& Sons, New York, pp 423-452

Bell CC, Myers CP, Russell CJ (1974) Electric organ discharge patterns during dominance related behavioral displays in Gnathonemus petersii (Mormyridae). J Comp Physiol 92:201-228

Bennett MVL (1971) Electroreception. In: Hoar WS, Randall DJ (eds) Fish physiology, vol V. Academic Press, New York, pp 493-574

Bratton BO (1987) Signalling with the electric organ discharge in the teleost fish Pollimyrus isidori before and during reproductive behavior. $\mathrm{PhD}$ thesis, Universität Regensburg

Bratton BO, Kramer B (1988) Intraspecific variability of the pulse-type discharge of the African electric fishes, Pollimyrus isidori and Petrocephalus bovei (Mormyridae, Teleostei), and their dependence on water conductivity. Exp Biol 47:227-238

Bullock TH (1982) Electroreception. A Rev Neurosci $5: 121-170$

Crawford JD, Hagedorn M, Hopkins CD (1986) Acoustic communication in an electric fish, Pollimyrus isidori (Mormyridae). J Comp Physiol 159:297-310

Frisch K von (1938) The sense of hearing in fish. Nature 141:8-11

Harder W (1972) Nachweis aktiver (elektrischer) Ortung bei Mormyridae (Teleostei, Pisces). Z Tierpsychol 30:94-102

Heiligenberg W (1977) Principles of electrolocation and jamming avoidance in electric fish - a neuroethological approach. Studies of brain function, vol 1. Springer, Berlin Heidelberg New York

Hopkins CD (1986) Behavior of mormyridae. In: Bullock TH,
Heiligenberg W (eds) Electroreception. Wiley \& Sons, New York, pp 527-576

Kirschbaum F (1977) Electric organ ontogeny: distinct larval organ precedes the adult organ in weakly electric fish. Naturwissenschaften 64:387-388

Kirschbaum F (1984) Reproduction of weakly electric teleosts: just another example of convergent development? Env Biol Fish 10:3-14

Kirschbaum F (1987) Reproduction and development of the weakly electric fish, Pollimyrus isidori (Mormyridae, Teleostei) in captivity. Env Biol Fish 20:11-31

Kramer B (1974) Electric organ discharge interaction during interspecific agonistic behavior in freely swimming Mormyrid fish. A method to evaluate two (or more) simultaneous time series of events with a digital analyser. J Comp Physiol 93:203-235

Kramer B (1976a) Flight-associated discharge pattern in a weakly electric fish, Gnathonemus petersii (Mormyridae, Teleostei). Behaviour 59:88-95

Kramer B (1976b) The attack frequency of Gnathonemus petersii towards electrically silent (denervated) and intact conspecifics and towards another mormyrid (Brienomyrus niger). Behav Ecol Sociobiol 1:425-446

Kramer B (1976c) Electric signalling during aggressive behaviour in Mormyrus rume (Mormyridae, Teleostei). Naturwissenschaften 63:48

Kramer B (1978) Spontaneous discharge rhythms and social signalling in the weakly electric fish Pollimyrus isidori. Behav Ecol Sociobiol 4:61-74

Kramer B (1979) Electric and motor responses of the weakly electric fish, Gnathonemus petersii (Mormyridae), to playback of social signals. Behav Ecol Sociobiol 6:67-79

Kramer B, Bauer R (1976) Agonistic behaviour and electric signalling in a Mormyrid fish, Gnathonemus petersii. Behav Ecol Sociobiol 1:45-61

Kramer B, Weymann D (1987) A microprocessor system for the digital synthesis of pulsed and continuous discharges of electric fish (or animal vocalizations). Behav'Brain Res 23:167-174

Kramer B, Tautz J, Markl H (1981) The EOD sound response in weakly electric fish. J Comp Physiol 143:435-441

Lissmann HW (1958) On the function and evolution of electric organs in fish. J Exp Biol 35:156-189

Lissmann HW (1961) Ecological studies on Gymnotids. In: Chagas C, Paes de Carvalho A (eds) Bioelectrogenesis. Elsevier, Amsterdam, pp 215-226

Lücker H (1982) Untersuchungen zur intraspezifischen Elektrokommunikation mittels der Latenzbeziehungen und zur interspezifischen Elektrokommunikation mittels der artund aktivitätsspezifischen Entladungsmuster bei Pollimyrus isidori (Cuv, and Val.) and Petrocephalus bovei (Cuv. and Val.). $\mathrm{PhD}$ thesis, Universität Konstanz

Lücker H (1983) Species-specific discharge rhythms in mormyrids as a mechanism for species identification. Verh Dtsch Zool Ges 76:195

Lücker H, Kramer B (1981) Development of a sex difference in the preferred latency response in the weakly electric fish, Pollimyrus isidori (Cuvier et Valenciennes) (Mormyridae, Teleostei). Behav Ecol Sociobiol 9:103-109

McCormick CA, Popper AN (1984) Auditory sensitivity and psychophysical tuning curves in the elephant nose fish, Gnathonemus petersii. J Comp Physiol 155:753-761

Möhres FP (1957) Elektrische Entladungen im Dienste der Revierabgrenzung bei Fischen. Naturwissenschaften 44:431-432

Moller P (1970) Communication in weakly electric fish, Gnatho- 
nemus niger (Mormyridae): I. Variation of electric organ discharge (EOD) frequency elicited by controlled electrical stimuli. Anim Behav 18:768-786

Moller P, Bauer R (1973) Communication in weakly electric fish, Gnathonemus petersii (Mormyridae): II. Interaction of electric organ discharge activities of two fish. Anim Behav 21:501-512

Push S, Moller P (1979) Spatial aspects of electrolocation in the mormyrid fish, Gnathonemus petersii. J Physiol (Paris) $75: 355-357$

Rigley L, Marshall JA (1973) Sound production by the elephant nose fish, Gnathonemus petersii (Pisces, Mormyridae). Copeia 1973:134-136

Russell CJ, Myers JP, Bell CC (1974) The echo response in Gnathonemus petersii (Mormyridae). J Comp Physiol 92:181-200

Sachs L (1978) Angewandte Statistik. Springer, Berlin Heidelberg New York

Squire A, Moller P (1982) Effects of water conductivity on electrocommunication in the weak-electric fish Brienomyrus niger (Mormyriforms). Anim Behav 30:375-382

Szabo T, Fessard A (1974) Physiology of electroreceptors. In: Fessard A (ed) Electroreceptors and other specialized Re- ceptors in Lower Vertebrates. Handbook of Sensory Physiology, vol III/3. Springer, Berlin Heidelberg New York, pp 59-124

Szabo T, Moller P (1984) Neuroethological basis for electrocommunication. In: Bolis L, Keynes RD, Maddrell SHP (eds) Comparative physiology of sensory systems. Cambridge University Press, Cambridge, pp 455-474

Westby GWM, Kirschbaum F (1977) Emergence and development of the electric organ discharge in the mormyrid fish, Pollimyrus isidori. I. The larval discharge. J Comp Physiol 122:251-271

Westby GWM, Kirschbaum F (1977) Emergence and development of the electric organ discharge in the mormyrid fish, Pollimyrus isidori. II. Replacement of the larval by the adult discharge. J Comp Physiol 127:45-59

Westby GWM, Kirschbaum F (1982) Sex differences in the waveform of the pulse-type electric fish, Pollimyrus isidori (Mormyridae). J Comp Physiol 145:399-404

Wilson EO (1975) Sociobiology. The New Synthesis. Belknap Press, Cambridge

Zakon H (1986) The electroreceptive periphery. In: Bullock TH, Heiligenberg W (eds) Electroreception. Wiley \& Sons, New York, pp 103-156 